GREENPEACE

\title{
Proceedings of the Conference
}

\section{Epigenetics, Transgenic Plants \& Risk Assessment}

December 1st 2005, Literaturhaus, Frankfurt am Main, Germany 
Moch, Katja (Ed.) (2006)

"Epigenetics, Transgenic Plants \& Risk Assessment"

Proceedings of the Conference at December 1st 2005, Literaturhaus, Frankfurt am Main, Germany

Die Deutsche Bibliothek - CIP Cataloguing-in-Publication-Data

A catalogue record for this publication is available from

Die Deutsche Bibliothek

Layout title page: Hannes Osterrieder

Available at the Internet at: http://www.oeko.de/oekodoc/277/2006-002-en.pdf

ISBN-Nr. 3-934490-24-7

(C) 2006, Öko-Institut e.V., Box 5002 40, D-791028 Freiburg 
Inhaltsverzeichnis

Preface 4

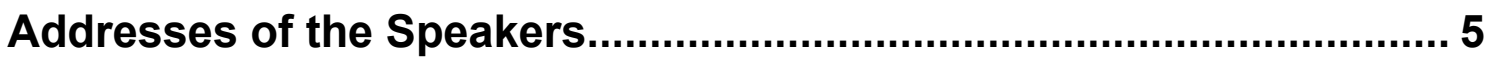

Christoph Then: Welcoming Speech .................................................... 6

Florianne Koechlin: Opening Speech...................................................... 8

Marcello Buiatti: Epigenetic Processes and the "Unintended Effects" of Genetic Engineering.

Cesare Gessler: Uncertainties and gaps in knowledge regarding genetic engineering of apple trees

Richard D Firn: The genetic manipulation of Natural Product composition - risk assessment when a system is predictably unpredictable.

Gilles-Eric Seralini: Genome Fluidity and Health Risks for GMOs ... 32

Arpad Pusztai: Facts behind the GM pea controversy 37

Irina Ermakova: Influence of genetically modified soya on the birth-weight and survival of rat pups

Manuela Malatesta: A diet based on genetically modified soybean affects cell functions in mice.

Beatrix Tappeser: A continuous challenge: Integration of state of the art knowledge into current risk assessment.

Outlook

Annex: Suggestions for the Risk Assessment of Transgenic

Plants 56 


\section{Preface}

On December $1^{\text {st }} 2005,70$ scientists, stakeholders and journalists from al over Europe met in the Literaturhaus in Frankfurt for the conference on "Epigenetics, Transgenic Plants \& Risk Assessments". Seven speakers highlighted from different perspectives

- the complexity of genome regulation and of the so-called secondary metabolism,

- inherent uncertainties of the genetic engineering of plants,

- the challenge of facing and coping with knowledge gaps

- $\quad$ and last but not least the implication that these uncertainties have.

30 years after Asilomar, the famous conference where scientists raised their concerns on the recombinant DNA technology in public and ten years after the first commercialisation of a genetically modified organism (GMO), scientists explained why the technology to create GMOs is not precise and not controllable. This has to be critically considered especially when transgenic plants are intended for commercial use because any uncertainty related with the transgenic plants will concern the public and the environment: The public because the transgenic crops, usually bulk products, enter ubiquitously the food chain and the environment because transgenic plants can reproduce, spread and evolve.

Just a little note on two articles in the proceedings: Though Manuela Malatesta unfortunately could not attend the conference, we herein present the article she has prepared in advance. Irina Ermakova presented some preliminary data on the influence of genetically modified soy on the birth-weight and survival of rat pups. Although it is realized that her data need independent confirmation, her presentation is included in the proceedings because of the potential importance of these data.

Statements and considerations of the speakers on the questions how arising knowledge on side effects or unintended effects of the genetic engineering of plants should be taken up in the risk assessment are summarised in the Annex. These proposals do not have to be considered as the best practice of a risk assessment but as a contribution to an ongoing discussion on how to evaluate GMOs.

I would like to thank Greenpeace and especially Christoph Then to make this conference possible and to give critical scientists the platform to present and exchange different opinions. And thanks to Florianne Koechlin for the spirited moderation of the conference! 


\section{Addresses of the Speakers}

Florianne Koechlin

Blueridge Institute

Blauenstrasse 15

4142 Münchenstein, Switzerland

Marcello Buiatti

Department of Animal Biology and Genetics

Via Romana 17

50125 Firenze.Italy

\section{Cesare Gessler}

Institute of plant sciences, Phytopathology, ETH-Zentrum LFW

Universitätstrasse 2

8092 Zürich, Switzerland

Richard D Firn

Department of Biology

University of York

York Y01 5DD, UK

Gilles-Eric Seralini

University of Caen and CRII-GEN

IBFA, EA 2608 SC-INRA

Esplanade de la Paix

14032 Caen - Cedex, France

Arpad Pusztai

GENOK

University of Tromso

Tromso, Norway

Irina V. Ermakova

Institute of Higher Nervous Activity and Neurophysiology RAS

Butlerov str., $5 a$

Moscow, Russia

Manuela Malatesta

Istituto di Istologia ed Analisi di Laboratorio, University of Urbino "Carlo Bo" via Zeppi s.n.

61029 Urbino (PU), Italy

Beatrix Tappeser

Federal Agency for Nature Conservation

Konstantinstr. 110

53179 Bonn, Germany 


\section{Christoph Then: Welcoming Speech}

Dear all!

I am very happy to open this first conference on epigenetics and risk assessment in genetically engineered (GE) crops in Frankfurt. As our program shows, experts from different scientific disciplines are involved in questions, which are related to questions concerning predictability of genetically engineered crops.

In the light of recent evidences on complex mechanism of cell and gene regulation, the current technology of manipulating the genome of crops look like as a pretty imprecise, crude and outdated technology without sufficient sound scientific basis. So 30 years after Asilomar, the famous conference where scientists raised their concerns on GMOs in public, and ten years after first commercialisation of GE seeds, we have still increasing figures of hectares were GMOs are grown on but also increasing doubts in their safety qualities.

We have alarming new evidences on possible heath effects as recent research from Australia shows. A new study has revealed that small unexpected and unpredicted changes in the structure of the protein produced by GE peas was responsible for causing allergic reaction in mice which also became more sensitive to other food allergies

This study shows that for example changes in protein structure can be very important in terms of toxicity and causing allergies. However, such changes in protein structure are not required to be examined in the risk assessments of GE crops in Europe or other regulation systems. Nor are comprehensive tests required on possible immune reactions.

On the opposite we have a list of crops, which already have market permission in Europe, but showed significant health impacts in animal feeding trials and were not investigated further. The shortcomings of the existing GMO risk assessment becomes clear when it is compared to test procedures used in authorising drugs.

In the latter, only a defined substance is usually tested - in accordance with a precisely described procedure to the point where clinical tests are carried out on human beings. For several reasons, this test procedure cannot be transferred to genetic plants.

- Plants are living systems whose characteristics change constantly as a result of processes such as growth, flowering, seed formation and environmental influences, whereas the quality of drugs must be stable.

- Interaction with the environment - outcrossing, spreading and impacts on complex ecosystems and so forth - does not have to be taken into account in testing drugs.

Companies like Monsanto, Bayer and Syngenta tend to deny the scientific reality for business reasons. Given the complex regulatory processes and many unsettled 
questions, molecular genetics is unduly simplified and reduced to commercially utilisable units. For Greenpeace it is unacceptable that, in an attempt to make profits with this technology, an incalculable risk to large parts of the biosphere is being run.

The genetically engineering of plants is compared very often with normal plant breeding and technologies such as inducing mutations by radiation or chemicals. But none of them breaks up of the regulation of cells and genes by crudely inserting new genes from different species into plants.

In contrast, normal cultivation and breeding maintains the orderly system as developed, tried and tested by evolution. It uses the great natural range and flexibility designed in biodiversity. The genomes of different species of plant can sometimes be re-combined, as with triticales, but such re-combination is limited to a few exceptions where the genetic regulation of plants does not make such exceptional steps in breeding impossible.

Even when the somewhat dubious methods of mutation breeding are used (using mutagenic radiation or chemicals), borders between species are not crossed, nor are plants directly forced into new metabolic pathways. The quality of plants created that way still seems to be dependent on their natural genetic background. You simply cannot create Bt plants by radiation.

But by conventional breeding you have a lot of other possibilities to create plants having more resistance against pest insects. Breeding based on natural biological diversity and using modern methods like genetic diagnosis (marker assisted breeding) seems to have the potential to be more efficient and reliable. I would like to quote Syngenta's research director David Lawrence from an article in "Die Welt" newspaper on 29 November 2004:

Traditional methods, he said, had proven themselves to his company as often being more effective than biotechnology. "We have experimented a lot with genetic engineering with seeds and plant protection, and have often failed." In contrast, he pointed to the exceptional success that had been achieved by traditional approach.

So Greenpeace hopes this conference is a help to overcome GMOs as a "dinosaur technology" and helps to move towards much better solutions around for future plant breeding than producing GE crops. 


\section{Florianne Koechlin: Opening Speech}

Probably you imagine Switzerland to be a curious and obscure little country, full of cheese and chocolate, banks and biotech companies and even not in the EU. However, in all cantons a majority of Swiss people voted at the referendum on November 27th 2005 in favour of a five years moratorium on commercial releases of GMOs. Even though government, parliament, industry, mainstream science and all right wing parties - which build a majority in Switzerland - were strongly against. Now a five years moratorium on the commercial release of GMOs is part of the Swiss constitution: A five-year pause to rethink risk assessment and also to look for innovative solutions without GMOs.

Rethinking risk assessment is our agenda today, too. For this conference Greenpeace issued a brochure that contains nine interviews with scientists, among them the speakers of today. ${ }^{1}$ In the interviews, I already tackled the questions of epigenetics, transgenic plants and risk assessment.

One of my interview partners was Professor Martin Heisenberg from the University Würzburg. I asked him if he could describe the function of a gene. His answer was: "That is without doubt one of the most open questions there is. A gene can have a lot of different functions; the number of its functions has no upper limit. A gene can also acquire new functions. This applies to all genes, those of humans, flies or plants.

When I learn Chinese, genes, which play a role in my language centre, will have new functions. If I then ask what functions these genes have, I have to ask if this is before or after I learnt Chinese. My learning Chinese will have bestowed particular genes in my language centre with new functions." This also means that the function of a gene goes far beyond coding particular proteins and that genes are highly context dependent, that they are ambiguous and that they can have many different functions, as Marcello Buiatti from the University of Florence explained: "The human genome has approximately 30,000 so called "coding genes" and these can code for more than 500,000 different proteins. Therefore, gene "ambiguity" - more proteins coded by a single gene - is very high, and is present at the level of transcription, between transcription and translation and also after translation due to post-translational modifications of proteins. Ambiguity, leading to plasticity of responses is made possible by the presence of many sophisticated mechanisms fixed throughout evolution - that's part of epigenetics."

Epigenetics is one of Marcello Buatti's keywords. So Epigenetics - "epi" meaning above - is a system being responsible for the regulating system on and control systems above the level of the genome.

1 Greenpeace (2005): Risk Underestimated. Interviews with nine scientists on genetically modified plants. http://www.greenpeace.de/fileadmin/gpd/user_upload/themen/gentechnik/greenpeace_genreader_englisch.PDF. 
Richard Strohman, retired professor at the Berkeley University, USA, explained in his interview the links between genes, epigenetics and cells. He said: "DNA has been called the Book of Life by Human Genome Project scientists, but many other biologists consider DNA to be simply a random collection of words from which a meaningful story of life may be assembled. In order to assemble that meaningful story, a living cell uses a second informational system. It is "dynamic" because it regulates changes in products over time, and it is "epigenetic" because it is above genetics in level of organization. And some of these changed products feed back to DNA to regulate gene expression. The key concept here is that these dynamic-epigenetic networks have a life of their own - they follow network rules not specified by DNA. And we do not fully understand these rules."

Perhaps one of the most intriguing new discoveries was that epigenetic systems build a bridge between the genome and the environment. Environmental changes can directly influence gene-expression patterns, thus the genetic level, through epigenetic systems.

A recent example: Pregnant mice were given special food supplements in early pregnancy. This affected the genes of the embryos. The new born mice had a different fur-colour, they were leaner and less prone to cancer. As if their genes "remembered" the food their mother ate during pregnancy. The scientists believe that epigenetic systems mediated these changes. In the meantime more examples of such direct environmental influences on the genes are known, also in plants. This however seriously conflicts with the old paradigm - the old central dogma of the gene as developed by Francis Crick in the early 19th century.

In an official Swiss document I found this definition some years ago: "A gene is a section of the DNA, which contains the information for one protein (...). By the way of these proteins, genes determine the structure as well as all metabolic processes of an organism." This is the old dogma. It basically means: One gene has one effect and it is always a one-way track from the genes to the protein. Genes are context-independent entities, always encoding the same protein. It's a one-track street from gene to protein to everything else. It's a seductive paradigm, and its beauty is its simplicity.

Epigenetics turns this picture upside down and leads to a complete reversion of hierarchy: Genes are not the ones controlling life processes, but rather suppliers of biochemical substances which the cell needs in its respective developmental or functional state. Genes are molecules like others as well, and the cell signals what is needed and where. Genes do not determine the program.

It's like you looked for a long time at a box from above on the outside and suddenly you look at it from below in the inside. It is a completely new way to look at life. It's not that the central dogma of the gene is wrong - it's only wrong in overseeing the limits of its validity, by referring to the genome as the book of life or the blueprint of life.

Where does this leave us in agro-biotechnology and transgenic plants? With the central dogma genetic engineering was said to be precise and predictable - we know the gene 
and we know the new organism and the sum of both cannot be more risky than each one of them.

Whereas - I will not go into this deeply - we all know that gene transfers are neither precise nor predictable. As Cesare Gessler from the ETH Swiss Federal Institute of Technology, Zurich puts it: "Genetic engineering has not been fully developed. The products of genetic engineering today are still at the level of a dinosaur technology. We use genes, which are foreign to a species, not knowing where they are inserted or what else will change in the whole chain from gene to protein. We don't know which regulatory relationships we're intervening in". Cesare Gessler, who supported the Swiss moratorium in the sake of science, argues: "Personally, I can't easily accept a fish gene in an apple. Nor would I like a 355 promoter, which comes from a virus, in my apple. And I don't find antibiotic resistance genes entirely acceptable either as this can produce problems with horizontal gene transfer for example. I don't necessarily believe there could be really big problems, but I simply don't feel comfortable with the idea." In a future time, he adds, with more sophisticated approaches, transgenic plants might be a valuable perspective.

In summary: While we have mounting evidences for epigenetics the outdated central dogma of the gene still exists - mainly in the field of agro-biotechnology and commercial applications of GM crops. We seem to hang in a state of suspense. The stubborn perseverance with which some still cling to the old dogma might have to do with commercial pressures and with patents. It's easier to patent genes than to patent complex epigenetic networks.

Before turning to implications for risk assessment - my third point - let me look at two phenomena which strike me as curious: The first is that there are relatively few studies on negative effects of epigenetics on transgenic plants. But this does not surprise Gilles-Eric Seralini of the Caen University in France. "When you study the role and regulation of genes, you undertake a lot of trials and you only select the GMOs that do not have these kind of problems. That means that $98 \%$ of all the GMOs that you produce do not function just because the gene might be methylated or it might be present but is not used normally by the organism, which received it. All the organisms that are modified but do not express the gene are put in the garbage. So you find very few studies on these issues. There are some papers about insertional mutagenesis in plants showing that artificial gene constructs may be more unstable than others. So I think that we should bear in mind that the study of the composition and the analysis and the substantial equivalence are far below the level of sufficiency to be able to predict any toxicity or any unintended effect of a plant."

The second point is: Worldwide, almost 100 percent of all transgenic plants cultivated throughout the world are either herbicide-tolerant or insect resistant, Bt plants. Only two traits, two traits which were developed in the eighties - you could say an amazing lack of innovation from industry. As some of my interview partners confirmed, this poor performance could have another deeper cause. The reason for the success of these two properties could be that their metabolic pathways are relatively isolated and do not 
interact with other ones. This is not the case with most other traits that will show interferences on the level of genetics, epigenetics as well as on the level of metabolism.

What are the impacts for risk assessment procedures? The philosophy underlying the laws and reglementations for risk assessment still depends on the central dogma. A thorough re-evaluation of previous assumptions never took place.

In the last few years there were attempts: impacts of so called "unintended effects" were cautiously acknowledged and introduced, be it in Codex Alimentarius, OECDreglementation, the Biosafety Protocol or the EU Directive 2001/18 on releases or the 'food and feed' regulation 1829/2003. But if the whole body of risk assessment theory is based on flawed assumptions it is also flawed. l'll point at some problematic areas some broad cracks in today's theory of risk assessment.

First crack: Today a company has to test a GMO for its impacts on beneficial insects or ecological effects - in just one place. So Monsanto tests its new Bt-maize in Missouri and claims validity of the results in Sweden or Kenya. Beatrix Tappeser from the German Federal Agency for Nature Conservation requires in her interview that every application for commercial release should include data from diverse climatic and ecological conditions and from several years. New findings in epigenetics point strongly to the need of such a request.

Second crack: Today mandatory toxicity tests are not prescribed for GMOs. "I think it is stupid to give GMOs to people for an entire life time," says Gilles-Eric Seralini, "when at the same time there is no requirement to undertake toxicity tests even for three months. So we should force industry to publish their results and we should enforce such long-term tests." But then there is the problem that I feel ambiguous about long term animal experiments to test GMOs not having much benefits - but this is another discussion.

Another crack: Richard Firn from the University York says that enzymes of the secondary metabolism present an additional layer of uncertainty, hardly looked at up to now. The general believe is that an enzyme is substrate specific, e.g. produces one specific product. That is what I learned at the University. But this theory is only correct for enzymes of the primary metabolism. In contrast, enzymes of secondary metabolism can be multifunctional, much like genes. One enzyme can produce many different products. So a gene transfer affecting the secondary metabolism can have highly unpredictable consequences. It is predictably unpredictable.

His conclusion is:" "It would be nice," he says, "if there was a greater humility and more experts would admit the limits of their knowledge." Or as Albert Einstein said: "We cannot solve problems by using the same kind of thinking we used when we created them." 


\section{Marcello Buiatti: Epigenetic Processes and the "Unintended Effects" of Genetic Engineering}

Epigenesis may be operationally defined as a variable set of processes occurring during life cycles, whose instructions are not univocally defined before birth. Such a definition implies the concept of genome "ambiguity" (more than one phenotype from one genome) and the increase of information during development (Waddington 1953).

Both concepts strikingly change the image of living systems generally presented as equivalent to computers endowed of a single program already "written" in the genome. Elements of that now obsolete vision are the deterministic nature of life cycles, the machine-like independence of living systems components, the "passive" and wholly predictable nature of organisms. Technologies derived from these concepts are all based on the assumption that, once known the sequence and the function of one gene in one organism, they will both remain the same in another, be it of the same or of a distantly related species. This assumption implies then that the fate and the effects of a transferred gene (a transgene) should be wholly predictable before the transformation. Although many data contrary to that vision have been collected and a non-mechanistic body of thought has been already present since the early fifties of the last century, there is no doubt that the very high resolution power of nowadays molecular biological techniques leading to genome sequencing have led to surprising progresses in understanding the dynamic processes of life.

Now we know that organisms live because they have developed during evolution a number of processes allowing them to change in response to inner and outer signals, thus modifying continuously their projects and adapting them to their histories of life. In other words we know now that the "benevolent disorder of life "by which I mean the capacity to maintain the living state through changes in the programme, is the basis of adaptation. The "explorative strategies" of living beings are now known to be based on "variability generators", which actively create variability at the different levels of organisation, and on processes, which allow the choice of a fitting complementary compound according to needs. Both, variability generation and choice are based on recognition of internal and external signals through communication between molecules.

Mechanisms of plasticity occur at the genetic and epigenetic levels. At the genetic level, the presence of hypervariable regions in DNA is related to gene function, like for instance in the cases of immunoglobulin and cadherin genes which require both a high amount of somatic variation, the first to recognize high numbers of unknown antigens, the second to allow the formation of a variety of neuronal connections and combinations. Programmed and not programmed sequence rearrangements, like the process controlling sex determination in yeast and the recently discovered DNA shuffling by transposons and retroposons in maize genomes also form part of the genome plasticity. 
At the epigenetic level plasticity is due to several processes. In the first place, different gene combinations can be expressed at different times and / or following the reception of different signals from the cell or from the environment. Moreover, genes can be "ambiguous" in the sense that each of them can use differently its information to give more than one protein. This can be done through differential "reading" the genetic message starting and ending at different points of the sequence, or through alternative splicing, i.e. shuffling of RNA exons giving rise to different mature RNAs from the same initial gene transcript. Even at the protein level different conformations of the same protein coded by the same genes may allow the performance of different functions as in the BSE syndrome and in many other cases like that of calmodulin, a protein with more than thirty potential functions. Finally, mechanisms of semi-permanent change of expression levels in plants can also be transferred to the progeny, such as DNA methylation and DNA amplification.

However, in the plasticity yielding processes as well as in biological networks dynamics, the elements must be connected and the networks follow "harmony rules" fixed during evolution. Connection rules, while allowing fast transfer of signals and efficient reactions to environmental and internal changes, render living systems very resistant to random noise but very susceptible to changes in "key components" connected with sectors of significant size of the network.

This is one of the main reasons of the "unintended effects" of the transfer of genes and sequences from one organism to another one distantly related, in the sense that the host may react in an unpredictable way thus preserving its harmony and plasticity. The lack of control of the integration process itself is the source of the unwanted variability. Additionally, rearrangements of the inserted sequence and unpredictable reactions of the metabolic network cause unwanted variability in genetically modified organisms. Factors playing a role in the lack of predictability of the presence of unwanted variation are the absence of reliable techniques that allow the control of the number of copies inserted, their localization in the genomes, their effects on the parts of the genome where they happened to be inserted etc. However the variability is also increased by the effect of in vitro culture periods generally needed for the regeneration of transgenic plants and by the effect of host plant reactions. At the genetic level, they involve frequent rearrangement of the inserted sequences, the regulation of their expression also through methylation and amplification, the addition to synthesized proteins of unwanted compounds eventually changing their functions and finally, the interaction of newly synthesized proteins with the existing metabolic network. All these processes are documented not only by experimental evidences obtained in ad hoc experiments but also by the molecular analysis with modern methods of some of the unintended effects observed in commercialised transgenic crops. Unpredicted sequence rearrangements and unexpected metabolic changes yielding non-productive crops and animals have been shown to occur in a number in a number of cultivars accepted for release in the market. 
The conclusion to be finally drawn from all the results described is that present day genetically modified plants are the result of the obsolete technology of the time of their development, nearly twenty years ago and that such technology has not yet been updated in coherence with the new knowledge gained in the last ten years or so, for reasons not related to science but rather to complex market and commercial dynamics. This conclusion should lead to a co-ordinated effort to update the methods of control of the genetic structure and function of present day and future GMOs and to drastically change consequently the sets of data required by the European Commission to be included in applications to the release into the environment and into the market of genetically modified products. In view of the existing literature in this field a particular attention should be devoted to third generation plants designed to produce pharmaceutical products particularly dangerous in the case of open field cultivation of GMPs.

Waddington CH (1953): The strategy of the genes. George Allen \& Unwin, London 


\section{Cesare Gessler: Uncertainties and gaps in knowledge regarding genetic engineering of apple trees}

Apple is a major commodity crop of the temperate zone. Until about 100 years ago apple trees were planted as single trees in the meadows assembling a large varied range of genotypes (cultivars). With the industrialization and later with the development of nanifying rootstocks single cultivar orchards started to be planted. This led to a dramatic increase in pathogen and pest problems. Especially pathogens were favoured by the presence of a genetically homogeneous host population with close tree proximity. Subsequently apple scab, a fungus that grows on the epidermis damaging the fruits, increased from a tolerable rather cosmetic disease to a factor that was able to destroy the whole crop. Contemporarily farmers and industries developed control measures based on chemicals toxic to the fungus (fungicides), first copper in various formulation later synthetic and continually more specific chemicals (MacHardy et al. 2001).

Today in organic farming copper fungicides are still used with up to $6 \mathrm{Kg} / \mathrm{year}(\mathrm{CH} 3$ $(4) \mathrm{Kg}$ ), in Integrated or conventional production 10 to 12 treatments with specific (synthetic) fungicides are the rule. Thus, apple is in Europe the most intensively treated culture. However parallel to this evolution, researchers started to be interested in the evident resistance of some wild Malus accessions. Crosses with various domestic apple cultivars led, on one hand to the discovery of a series of dominant major scab resistance genes and on the other hand to the selection of genotypes resistant to scab with most characteristics of a domestic apple. Today after over 90 years of breeding efforts a range of scab resistant cultivars is available, however most base their resistance on a single gene named $\mathrm{Vf}$ originating from the Malus floribunda tree number 821.

Even if the advantage of a scab resistant cultivar is evident, resistant cultivars do not yet dominate the market. The cause is simple, apple is sexually self-incompatible, in other words a flower from a particular cultivar can only be fertilized by the pollen of another cultivar. This results in the fact that the seeds will be always different from the mother and father as well as between themselves, each seed is genetically unique and if selected will be a new unique cultivar with properties considerably different from the mother tree. This is a relevant limitation in apple breeding, each time we would like to introduce a new trait, mostly resistance to a pathogen, not only is a completely different genotype and therefore phenotype created in the first offspring generation, but backcrossing with one of the ancestor is not possible (or only to a very limited extent). Therefore to eliminate unwanted wild genome parts a very time consuming pseudobackrossing with different domestic cultivars is necessary. Even if modern DNAanalysis methods such as genetic maps, identification of DNA-markers linked to traits of interest and marker assisted breeding, can help and accelerate the process, a new cultivar with fruits possessing a new taste and storage/conservation capacity, new tree 
form and growth pattern will be created with finally a new name. Last but not least this new cultivar also needs consumer acceptance, who often stick to certain cultivars.

Moreover if not a single gene (single trait) has to be introduced but several such as resistance to mildew, to fire blight or several genes for a single trait (several resistance genes against a single pathogen to achieve durable resistance) it becomes an almost impossible endeavor.

Under these premises, the introduction of a specific gene into a particular cultivar which already has all qualities necessary, except the trait in question, is attractive. Recombinant DNA technology (gene technology) promises to do exactly this. The first target was fire blight and in a pioneering work Aldwinckle (Norelli et al. 1994, Ko et al. 2002) demonstrated that the incorporation of various micro-organism derived lytic enzymes genes into the cultivar Royal Gala rendered the plants more resistant to artificial inoculation in greenhouse and field trials. Similarly the incorporation of fungal chitinase genes and a glucanase gene led, in some transgenic lines of the cultivar Mclntosh, to high resistance against scab, however often unintentionally associated with reduced plant vigour (Wong et al. 1999, Atkinson et al. 2002, Bolar et al. 2000). At present, no reports on the possible side effects of the gene products (on beneficials such as hyperparasitic insects, mycorrhiza) are available. In these experiments gene expression was controlled by the $35 \mathrm{~S}$ promoter (from CaMVirus) and selection was achieved through the use of the nptll (kanamycin resistance) gene

With the same technique (promoter CaMV-35S, selection gene nptII) we introgressed the $\mathrm{Vf}$ resistance gene HcrVf2 into the scab susceptible cultivar Gala (Belfanti et al. 2004). We demonstrated that HcrVf2 was fully functional, rendering the selected transgenic lines resistant to scab using the common field inoculum and being susceptible to race 7 which is able to overcome the resistance of M. floribunda 821 the source of Vf. Additionally we showed that substitution of the CaMV-35S with the promoter of the apple resistance gene $\mathrm{Vf}$ is feasible and functional (Silverberg-Dilworth et al. 2005). Recently another research group also introgressed the Vf-gene using an apple own promoter instead of the $35 \mathrm{~S}$ (personal communication Aldwinckle).

These works show that it is possible to control scab by introgressing, through DNA recombination technology, foreign genes or an apple own resistance gene. Scientifically this is certainly a progress and one may be tempted to proclaim the conquering of scab and that the application of fungicide to control it will soon be obsolete. However several obscure aspects must be regarded. Biosafety aspects of expressed target proteins (especially if foreign) must be evaluated. Major effects on non target organisms can be evaluated, however subtle effect may only be detectable after long observation in orchards and may harbor unpleasant surprises. Using the apple's own resistance gene $\mathrm{Vf}$ (controlled by its own promoter) where recognition of the incompatible pathogen genotypes is demonstrated and no negative effects are present (as it is used in many scab resistant cultivars) can avoid at least these risks. 
Three main problems remain to be addressed: durability of the resistance, selection markers and epigenetic effects of the insertion site.

A constraint is the use of a single resistance gene: as we know, a particular race of the pathogen can nullify its effect, so that such a transformed, popular, cultivar if successful, would soon become susceptible again as it would force the pathogen population to change from avirulent to virulent. This constraint can be overcome by introgressing one or more functionally different scab resistance genes, similarly to the efforts in conventional breeding today. A transformed cultivar has the advantage of maintaining the original cultivar characteristics and clearly requires less time and costs.

The second problem derives from the use of the selection gene (marker gene). It is absolutely necessary to have a system which allows survival of the transformed cells and eliminates the non transformed cells which highly outnumber the former. Currently antibiotic resistance or herbicide resistance genes are the most popular selection genes. The antibiotic resistance system will soon no longer be allowed, the herbicide (glyphosate) even if much used, is questionable. Other systems are available but require further improvements and still use foreign genes. The current technology therefore has to be superseded by a technology which allows removal of the selection gene. In plants which are amenable to further crosses such as rice or wheat this is possible but in the case of apple it would nullify the scope. Such new technologies are currently under development in several public research institutions (USDA, HortResearch NZ) and may be available in a few years, hopefully not protected by patents.

The third major and usually not addressed problem is the insert site. (The insert site is as far as we know random with certain preferences). At present, targeted insert into plant genomes, for example via homologous recombination, is not possible. In each transformation event the insertion site will be different. Clearly lines with the insertion in a vital allele or allele governing visible traits are eliminated. However subtle changes in gene expression at the site of insertion may become visible only in the later stages of the plant development. Even if only speculative, the random introgression of any gene may cause silencing or even expression of genes which usually are or are not expressed at a particular stage. Such epigenetic effects if they alter the plant visibly can be easily detected but it is much more difficult to identify changes in expression of compounds with an effect on non target organisms. Again drastic changes may be recognized but, even if remote as a probability, subtle changes may be detected only after large scale planting and use of such transgenes.

What solution can be proposed that provides a definitive response from testing of all possible unwanted epigenetic effects? The probability is minimized if the inserted gene and promoter are placed into their natural site in which they are located in the conventional scab resistant cultivars. We know this exact position, however we lack the tools to insert a gene exactly where desired or even better to replace a specifically targeted allele. Again efforts are underway to develop such tools (USDA, Cornell- 
Univ.). However, even an estimation of when they will be available in model systems and later applicable to apple is difficult.

Concluding I may state that an apple transformed with only apple own DNA and a substitution of non-functional resistance genes (overcome by all common races of the pathogen) with two or more functional resistance genes may be acceptable (gene therapy). Such apple cultivars will be a contribution to a safer and environmentally sustainable apple production, as the input of fungicides could be drastically reduced. Additional safety questions such as outcrossing, weediness have to be discussed but may loose their relevance as such cultivars will be principally identical to resistant cultivars obtained through traditional breeding.

However, to reach this goal great advances in the DNA recombinant technology are needed and are currently still out of reach. The current available technology yields products which are, from many points of view, questionable and therefore not ready to be released. However we should not condemn the technology but develop it so that the delivered products meet safety requirements and are truly useful to the community.

\section{References:}

Atkinson RG, Schröder R, Hallett IC, Cohen D, MacRae EA (2002): Overexpression of Polygalacturonase in transgenic apple trees leads to a range of novel phenotypes involving changes in cell adhesion. Plant physiology 129: 122133.

Belfanti E, Silfverberg-Dilworth E, Tartarini S, Patocchi A, Barbieri M, Zhu J, Vinatzer BA, Gianfranceschi L, Gessler C, Sansavini S (2004): The HcrVf2 gene from a wild apple confers scab resistance to a transgenic cultivated variety. Proceedings of the National Academy of Sciences of the United States of America 101(3): 886-890.

Bolar JP, Norelli JL, Wong KW, Hayes CK, Harman GE, and Aldwinckle HS (2000): Expression of endochitinase from Trichoderma harzianum in transgenic apple increases resistance to apple scab and reduces vigor. Phytopathology 90:72-77.

Ko K, Norelli JL, Reynoird J, Brown S (2002): T4 Lysozyme And Attacin Genes Enhance Resistance Of Transgenic 'galaxy' Apple Against Erwinia Amylovora (BURR.). Journal Of American Society Of Horticulture Science 127, (4): 515-519.

MacHardy WE, Gadoury DM, Gessler C (2001): Parasitic and biological fitness of Venturia inaequalis: relationship to disease management strategies. Plant Disease 85(10): 1036-1051.

Norelli JL, Aldwinckle HS, Beltran LD, and Jaynes JM (1994): Transgenic 'Malling 26' apple expressing the attacin $\mathrm{E}$ gene has increased resistance to Erwinia amylovora. Euphytica 77:123-128.

Silverberg-Dilworth E, Besse S, Paris R, Belfanti E, Tartarini S, Sansavini S, Patocchi A, Gessler C. 2005. Identification of functional apple scab resistance gene promotors. Theoretical and Applied Genetics 110: 1119-1126.

Silverberg-Dilworth E, Patocchi A, Broggini, G.A.L., Belfanti, E, Paris, R. Tartarini, S. Gessler C (2005: The apple scab resistance gene HcrVf2 forms race-specific interactions with Venturia inaequalis. Phytopathology submitted. 
Wong KW, Harman GE, Norelli JL, Gustafson HL, and Aldwinckle HS (1999): Chitinasetransgenic lines of 'Royal Gala' apple showing enhanced resistance to apple scab. Acta Hortic. 484:595-599. 


\section{Richard D Firn: The genetic manipulation of Natural Product composition - risk assessment when a system is predictably unpredictable.}

"Nothing in biology makes sense except in the light of evolution" (Theodosius

Dobzhansky).

\section{Introduction}

If a biologist looks at an ecosystem, an organism, a cell or an organelle they can usually see some patterns or order that fits within a larger evolutionary framework and they can use that framework to interpret what they are seeing. It is the understanding that biologist have gained by studying the working of systems at all these levels that gives them some confidence in predicting the possible consequences of interfering with any of these processes. Yet if a biologist is shown a map of all known biochemical pathways they are unlikely to see any patterns - to most biologists it is just a collection of names and arrows. There is much knowledge, and some understanding, of many individual enzymes and most biochemical pathways but how and why has evolution shaped biochemistry as an entity? If we cannot answer that question how can we confidently predict the outcomes of attempts to change an organism's biochemical repertoire by genetic manipulation?

\section{Why might one want to genetically manipulate Natural Product composition?}

Most plant and microbial species make a unique mixture of chemicals - that is why many plants and fungi can be identified by their taste or smell. The chemicals that give each species its unique chemical identity are termed Natural Product (sometimes also called Secondary Metabolite). The total number of Natural Products identified is approximately 100,000 and there could be over 500,000 different molecules being made in the natural world. Although Natural Products may make up only a few percent of the total carbon in any plant, the total amount made annually in the world might exceed a billion tonnes. Thus the natural world has a larger and more diverse chemical capacity than the chemical industry.

Throughout history humans have valued individual Natural Products very highly indeed to the extent that the trade in just a few of these Natural Products (spices, tea, coffee, cocoa, tobacco) have enriched individuals, cities and nations. However, Natural Products not only enriched lives they also saved them. Before the 20th Century, Natural Products were the most important chemicals used to treat ailments and diseases. Even in the 20th $\mathrm{C}$, the most important antibiotics, and some of the most successful anticancer drugs, were Natural Products.

Although the value of some Natural Products to humans is easy to judge, the value of each and every Natural Product to their producers is much harder to evaluate. 
However, there is agreement that some Natural Products play an significant role in influencing the fitness of organisms that interact with the producers of these chemicals. The attractiveness, or unattractiveness, of plants to insects for example depends partly on the scents and flavours given to the plant by its Natural Products. Some Natural Products also play a role in defending plants against microbial attack. Given that insects pests and fungal pathogens continuously compete with humans for crop products, and given the public suspicions of all synthetic pesticides, there is an interest in finding ways of using natural chemicals to defend crops. The manipulation of the Natural Product composition of crop plants could be one way of trying to enhance the resistance of plants to insect or fungal attack and such work is already underway.

Clearly the value of just a few of the Natural Products that humans have been able to access to date is sufficient to focus an interest on the genetic manipulation of the biochemical pathways leading to such products. However, many potentially valuable Natural Products are inaccessible because there is no way of commercially producing the organisms that make them. It will be tempting to move the genes that code for the enzymes that make such products into organisms that can be grown commercially. It is timely to consider what the impacts of such manipulations of Natural Product biosynthesis might be.

\section{Why might the genetic manipulation of Natural Product pathways be unpredictable?}

If one combines the classical "One Gene - One Enzyme" hypothesis, which won Beadle and Tatum the Nobel Prize in 1958, with the generally accepted view of most biochemists that every enzyme has evolved to convert one substrate to one product, it seems logical to conclude that the addition of one gene will add one new product to a cell. However, this simple view of biochemical engineering has been challenged, first theoretically, and more recently experimentally.

The theoretical challenge is based on the recognition that evolution acts to shape the map of biochemical pathways by selecting initially on the properties of the chemicals made by the enzyme and not directly on the properties of the enzyme itself. A mutational event can give rise to a new protein in a cell and if that protein is an enzyme, the fitness of the mutated organism will depend on the cost of producing the new product and the benefit that that new product brings to the cell. What properties do chemicals give to cells that could act as a focus for selection?

\section{What determines the fitness of a mutant making a new chemical?}

Consequences for an individual that has a new synthetic ability that produces only one new chemical depends on the intrinsic properties possessed by that substance, not the properties of the mutated enzyme, that will be the initial focus for selection (Figure 1). The new substance could:

- possess properties that are new and enhance the functioning of the cell and hence the organism 
- possess properties that are new and adversely affect the cell and hence the organism

- possess properties that are new but have no impact on the functioning of the cell or the organism other than the imposed metabolic cost of production

- possess properties that can substitute for an existing, necessary property with no impact on the functioning of the cell or the organism other than the imposed metabolic cost of production, but with the accrual of potential functional redundancy

- possess properties that can substitute for an existing, necessary property with a negative impact on the functioning of the cell hence the organism (via, for example, diversion of substrates)

(a)

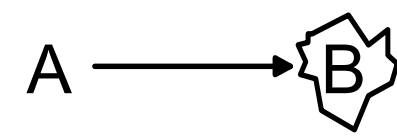

(b)

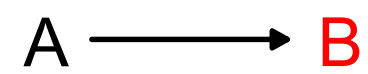

Selection on intrinsic property biomolecular activity

Selection on intrinsic property physicochemical such as colou

(c) $\mathrm{A} \longrightarrow \mathrm{B}$

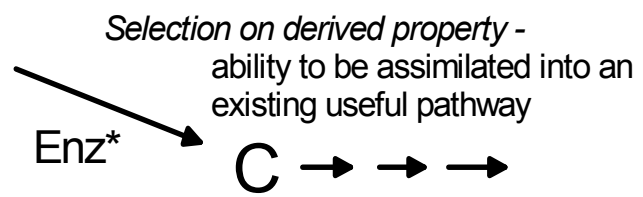

Fiome 1

If the new molecule possesses intrinsic properties giving an organismal cost/benefit $<1$ then selection will favour the retention of individuals possessing that variant. Variants with a cost/benefit $>1$ will be lost from the population. However, what happens if the new substance is converted into a second substance by an existing enzyme? Now selection can act on the intrinsic property of the original new substance and/or the intrinsic properties of second new metabolite(s).

\section{What molecular properties are subject to selection?}

Biomolecular activity - Natural Product pathways leading to physiologically active compounds (Fig.1 a)

Because of the nature of protein/ligand interactions, it is necessary for a ligand to have a structure that precisely fits the binding site on the protein with which it interacts. The fit must be precise enough to give a binding affinity for the protein/ligand complex such 
that a significant occupation of the binding site occurs when the chemical is present at its physiological concentration. These are very strict constraints and therefore very few chemicals arising via mutation will possess the appropriate structure to bind to a protein when both are present at low concentrations. Firn and Jones have defined the ability of a chemical to interact with a protein at low concentrations, such that the function of the protein is affected, as biomolecular activity to distinguish it from the less well-defined term biological activity [4]. The low probability of any chemical possessing potent biomolecular activity must have been a severe evolutionary constraint on the ability of an organism to have enhanced fitness by producing chemicals with potent biomolecular activity. Consequently it was proposed ${ }^{2}[5,6]$ that the capacity to generate new chemical diversity would have been a general trait that was selected for in organisms making such chemicals. A greater chemical diversity begets a higher probability that a mutant will have a compound with beneficial biomolecular activity. It was also proposed that metabolic traits that fostered the retention of existing chemical diversity, even in the absence of a current role for some products, would have also been selected for, provided the current cost of production was outweighed by the current benefits.

\section{Specific physiochemical properties - pathways leading to chemicals with a beneficial physicochemical property (Figure 1b)}

When chemists began to isolate and characterise the chemicals found in organisms, they often grouped chemicals sharing similar physicochemical properties into broad groups - pectins, hemicelluloses, polysaccharides, lipids, carotenoids, flavonoids and phenols. The shared physiochemical properties of a group enabled them to be extracted or quantified together. For all such broad classes of naturally occurring molecules, a considerable diversity of individual chemical types within the group was found. Why does one organism make such a diversity of lipids, carotenoids or polysaccharides? Why does one bacterial species make a different spectrum of lipids compared to another species? The answer to both questions is that it is a physicochemical property that is being selected for and because that property is not strictly linked to the detailed fine structure of the molecule a wide tolerance for structural variation exists. If the new and the old products share similar physicochemical properties, then there is a reasonable chance that the mutation will be selectively neutral at worst (assuming only a trivial increase in production costs). It is therefore predictable that if certain types of physiochemical properties are useful to cells, but the properties are not highly structure-specific, then a diversity of chemical types will be found within a single organism and different organisms will tend to possess a different mix of these chemicals. Indeed, there may be an advantage to an individual organism in producing such chemical diversity if the chemicals being made play a role in excluding other organisms from the cell or organism (e.g. the cell wall, the

\footnotetext{
${ }^{2}$ This model was given the name "The Screening Hypothesis" to draw attention to the analogy with the screening activities carried out by pharmaceutical and agrochemical companies. Because potent, specific biomolecular activity (or biological activity in all its forms) is a rare property for any one molecule to possess, such companies screen huge libraries of chemicals using robotics in order to find the rare valuable chemical.
} 
cuticle). For example, microorganisms seeking to invade plant cells have to degrade the cell wall and a chemically diverse cell wall would be expected to be less susceptible to degradation that a chemically homogeneous one.

The prediction that chemical diversity will be tolerated in compounds serving a largely physicochemical role is supported by a number of recent studies of Arabidopsis plants. Certain carotenoids can be absent without apparent effect [7]. Some individual fatty acids are not essential for growth, development and photosynthesis [8]. Changing the cuticular waxes need not have an adverse effect [9]. It is evident that there is a large degree of substitutability within these classes of compounds.

The chemical diversity found in the groups of chemicals retained for their physicochemical properties would also be a valuable resource as a pool of chemical diversity to be drawn upon for the generation of new physiologically active compounds (i.e., biomolecular activity). There is evidence consistent with this concept. The internal cell regulators IP3 and diacylglycerol are derived from a lipid [10] as are prostaglandins [11] and the jasmonates [12]. The carotenoid pathway serves to provide the precursor of abscisic acid [13] and the fungal mating substance trisporic acid [14]. There are numerous examples of small molecules derived from cell walls possessing biological activity which may be important in plant-microbe interactions [15].

Derived properties - pathways involving the basic metabolic pathways of most cells (Figure 1c).

In contrast, a lack of diversity is partly what characterises "primary metabolism". It is proposed that the key feature in the evolution of primary metabolism is that selection would not have acted on the intrinsic properties of new molecules that arose through mutation. Instead selection will operate on the collective functioning of the pathway resulting in conserved metabolism, canalization and enzyme specificity.

Two alternative ideas have been advanced to explain the evolution of "primary metabolism". Horowitz [16] postulated that biochemical pathways leading to the building blocks necessary for the production of structural and informational molecules (RNA, DNA) evolved 'backwards'. New enzyme variants that could introduce appropriate molecules into the evolving pathway would be highly beneficial and would be strongly selected. This would be an extreme example of what we define as selection of a derived trait, in that each new variant contributes to fitness by improving the efficiency of production of a substance that already possesses a useful property. An alternative model, where diverse and random biochemical transformations, generated a coordinated function by chance [17] is an even more extreme version of a property being derived - in this model the derived property resides within the unique collective properties of all the components. The important featured shared by both these models is that "primary metabolism" would first have evolved because chemical diversity was available and was then being extended by chance events. Once a self-replicating structure evolved, the main biochemical processes involved in the production of that structure would be severely constrained. A new enzyme variant arising which could 
produce a new molecule from a common, important precursor in a cell would be likely to have adverse consequences to the organism simply as a result of disrupting the flux of material through that pathway. Although gene duplication can allow for extending rather than substituting chemistries, competition for substrates would have existed and would usually be highly detrimental. The new product might also have sufficient structural similarity to an existing metabolite that it might act as a substrate analogue for another enzyme or act as an allosteric inhibitor, both of which might have had adverse effects on the cell. These types of constraints will have been very severe for all pathways through which there is a high flux and which are necessary for cell homeostasis. Because the selection pressures operating on this type of pathway are so different from those operating on pathways leading to molecules selected on the basis of their intrinsic properties, it is predictable that metabolic traits will differ. For example, high substrate specificity is predictable in enzymes participating in this type of metabolism.

\section{The implications of this model for manipulation of Natural Products}

If the evolutionary model outlined is valid, biochemistry becomes a subject where uncertainty is partly designed into some parts of the overall system. There will be pathways where evolution will be favouring the reduction of uncertainty and pathways where flexibility and uncertainty is selected for. Consequently the addition of a gene coding for an exotic enzyme into an organism must inevitably carry with it a probability of an uncertain outcome. A detailed knowledge of the properties of the enzyme in its native organism is only partly useful because it is the properties of the enzyme in its new biochemical environment that will determine which chemicals it transforms and at what rate. This problem is most acute when manipulating pathways involved in Natural Product synthesis because it is already known that single gene mutations in enzymes involved in such pathways can result in multiple, sometimes unexpected, changes in chemical composition (23).

Not everyone accepts that the evolutionary model outlined above makes the genetic manipulation of plants unpredictable. Kutchan (19) concluded that plants can be tailored in a rational manner with marginal effects and hailed the work of Kristensen et al. (20), as being a milestone in the public acceptance of genetically modified plants. The elegant studies of Kristensen et al. showed that it was possible to add genes coding for enzymes responsible for the synthesis of an exotic secondary metabolite (dhurrin) to a plant (Arabidopsis thaliana) with no evident developmental or morphological consequences and only very minor changes in the chemical composition. This finding would seem to counter the argument advanced some years ago (21) and summarised above. However, when one looks closely at all the results from the various genetic manipulations studied by Kristensen et al., it is clear that rather that providing evidence inconsistent with the model outlined, their work shows that the addition of certain genes results the types of changes that we predicted. Kristensen et al. showed that the addition of a functional metabolon (a group of 
enzymes spatially oriented in with respect to each other) can reduce the opportunity for inherently promiscuous enzymes to act on the exotic new intermediates. Such metabolic channelling of some stages in secondary product metabolism may well be the result of evolutionary selection tempering the inherent capacity of secondary metabolism to generate chemical diversity. However, there is evidence that such channelling is not universal (22). The advantage of evolutionary selection favouring the metabolom strategy of reducing the impact of enzyme promiscuity, rather than the alternative strategy of tightening the substrate specificity of the individual enzymes, is that a greater capacity for promiscuity can be retained and released by subsequent mutations. Indeed such "hidden pathways" were predicted as part of the Screening Hypothesis (6). Consequently the fact that one part of an exotic pathway can be inserted into a plant with predictable results by no means provides a universal lesson. Indeed the fact that Kristensen et al, and other studies (22), have shown that the introduction of some exotic genes causes unpredictable changes in secondary product composition shows that the unpredictability we predicted has been found. Consequently it is maybe premature to predict that the general public will be completely reassured by the results of Kristensen et al. (20).

In summary, both experimental evidence and the evolutionary model suggest that the manipulation of Natural Product pathways will often produce unexpected changes in Natural Product composition. Such manipulation will be predictably unpredictable. But can this unpredictability be compensated for by a more thorough study of the new Natural Product composition of a manipulated plant?

\section{Metabolomics - what it can and cannot tell us}

It is ironic that the term genetic engineering was adopted so readily and then the terms of engineering were used erroneously. For example the determination of the DNA base sequence of an organism does not provide a blueprint but an unstructured parts list. Worse still, the parts list includes many parts (genes) that are only used at certain times, or in certain places or under certain circumstances. Further uncertainty results from the fact that many descriptions in the parts list do not relate to parts but serve some other purpose (non-coding sequences). Responding to the uncertainties being uncovered by molecular geneticists, some biochemists studying the protein composition of cells, rebranded their subject as proteomics and concentrated on devising techniques that could provide quick, accurate and efficient means of establishing what they considered to be the only meaningful parts list of the cell - the protein composition. However, the contribution of one class of proteins, the enzymes, to the current status of the cell, was not easy to judge simply by their presence or absence. It was known that the presence of an enzyme protein in a cell did not reliably predict whether it was currently active or at what rate. A number of ways were known of regulating the activity of an enzyme, many of which were highly dynamic (for example feedback inhibition). Thus although proteomics could address some of the unknowns that genomics could not, uncertainties remained when judging the functioning of a cell. 
Recognising that the contribution of enzymes to the current status of a cell could possibly be best judged by measuring the products enzymes make, analytical chemists and biochemists rebranded their subject and metabolomics was born. Metabolomics is the study of the metabolome: the metabolome is the complement of all the small molecules in an organism:
"Metabolomics is a relatively new discipline and techniques for high-throughput metabolic profiling are still under development. No single technique is suitable for the analysis of all different types of molecule, so a mixture of techniques is used. Methods such as gas chromatography, high-pressure liquid chromatography and capillary electrophoresis are used to separate metabolites according to various chemical and physical properties. The molecules are then identified using methods such as mass spectrometry" (Wellcome Foundation)

While the term metabolome is fashionably recent, it is misleading to claim that it is a new discipline. The concept of analysing the chemical composition of organisms stretches back at least 200 years. Metabolomics is really little more than the dressing up of a previously unfashionable area of research in a modern cloak ${ }^{3}$. Clearly the renewed interest in the chemical composition of plants and microbes is to be welcomed but there needs to be a caution as to exactly what such an approach can deliver.

There are two questions that need to be answered:

- How easy will it be to complete a full analysis of a genetically manipulated plant or microbe?

- How can that information inform us about the risk that the plant presents to organisms that interact with it (humans and other organisms if plant or microbe is grown in an open system).

\section{The challenge of conducting a complete chemical analysis}

A chemist asked to analyse a sample will normally ask two questions:

- Which chemicals do you want to measure?

- At what level of sensitivity do you want the analysis to be conducted?

For theoretical reasons there can be no simple answers to these questions hence inevitably an element of judgement lurks beneath the subject of metabolomics.

The primary metabolites. The easiest types of chemicals to be analysed are those that occur in highest concentration and which are common to most organisms - the primary metabolites such as simple sugars, amino acids, common lipids, the common nitrogen compounds and many phosphorylated compounds. However, it is to be expected that many significant changes in primary metabolism will have already revealed themselves by changes to the development or morphology of the organism because it is

\footnotetext{
${ }^{3}$ We are currently in the "omics" era of biology, an era that has approximately co-incided with the great era of branding and where added value is associated with names rather than substance.
} 
predictable that most changes to the primary metabolism of an organism will reduce the growth rate of the organism. However, even such dramatic changes might be hard to interpret because the plasticity of plant development will enable a small localised change to be propagated into a larger ones as a result of alternative developmental pathways opening up for the whole plant. However, because so much of primary metabolism is shared by plants, it is not unrealistic to expect that methods will become available that can routinely, and largely automatically, report the concentration of the several hundreds of primary metabolites in a sample. The sensitivity of the analysis of the primary metabolites will also be relatively easy to judge because many of these compounds occur at relatively high concentrations and we have a large body of information available as to the concentrations that have already been reported. Likewise there is a considerable body of information available to judge the effect of changing the concentrations might be on the metabolic well being of the organism. However, because different organs, or indeed different cells, at different times, under different conditions will have very different metabolite concentrations, there can be no universal "metabolic analysis" for even a single organism. Thus the tools that facilitate the analysis will need sensible and considered use with the limitations and uncertainty of the analysis given some prominence.

Natural Products (Secondary Metabolites). These chemicals will inevitably be much harder to analyse because every plant and microbial species will possess a unique spectrum of chemicals. Hence unlike the methodologies being developed for the analysis of primary metabolites, the specific methodologies needed for a thorough analysis of the Natural Product composition of one plant species might be only useful for that species and its close relatives. Furthermore, because Natural Product metabolism is predictably unpredictable, an organism expressing an exotic gene coding for an enzyme involved in a Natural Product biosynthetic pathway, might be producing several unknown new structures. Looking for unknowns is a challenge and determining the structures of these new chemicals is a even greater challenge. Thus whilst the metabolomic analysis of primary metabolites might be built on a database with 1000 known primary metabolites, a metabolomic analysis of Natural Products might need a database 100-1000 fold larger - with the majority of that data currently unavailable.

\section{What can we deduce from the analytical data?}

As outlined above, it is predictable that any significant change to primary metabolism will very often result a deleterious effect on the plant or microbe hence are unlikely to be of commercial value. Furthermore, the majority of primary metabolites are unlikely to pose a treat to those that consume them. Most generalist organisms that consume plants or microbes have evolved the capacity to metabolise these chemicals, indeed their survival depends on the ingestion of these chemicals and it is normal for such organisms to vary the mix of these primary metabolites on a hourly, daily or seasonal basis. These consumers are likely to have evolved methods to tolerate large changes in the concentration of primary metabolites in their diet. Hence a metabolomic analysis 
of primary metabolites is not easy to justify on the grounds of human food safety but it could be more important in terms of judging any undesired effects on other consumers of the genetically manipulated product. For example many insects are highly specialised herbivores and will have evolved with a very consistent diet hence may not have a capacity to tolerate changes in the primary metabolite composition of their diet without a loss of fitness.

What might a metabolomic analysis of Natural Products of a genetically manipulated plant tell us about the wisdom of adopting the widespread cultivation of such a crop? This question cannot be answered in general terms because there will be so many unknowns and/or assumptions involved in producing an answer. In contrast to the case of plants with changed primary metabolite composition, where there are theoretical reasons to accept that the majority of consumers of the products will be pre-adapted to tolerate all but very large changes in primary metabolite composition, in the case of changes in the composition of Natural Product one cannot make any assumptions that the consumers will be pre-adapted.

Lets us assume that a genetically manipulated plant has been found by metabolomic analysis to produce 3 novel Natural Products in small amounts - say $5 \%$ of the mass of the major Natural Product normally found of that species. What understanding does this new piece of information given us in respect of the safety of this crop for humans or for other members of the natural world? There is a very high probability that these novel chemicals will have completely unknown properties consequently it will be impossible to say whether these chemicals pose a risk to any organism that comes into contact with the plant. The Screening Hypothesis predicts that the probability of any one of these chemicals possessing potent, specific biological activity (or more accurately biomolecular activity) is very low. In other words, at this stage of the analysis, the actual identification of the new chemicals offers little more reassurance that the theoretical underpinning of the subject overall. For the evidence to surpass the theoretical logic, precise toxicological studies of the new chemicals would be needed. To undertake such studies would require quantities of the new chemicals to be made or extracted. This in itself would be a considerable task if these chemicals occur at low concentrations or if these chemicals are very difficult to make in the laboratory (which many Natural Products are). Even if such studies were undertaken, given that similar toxicological data will be unavailable for the great majority of Natural Products that occur in the same plant, there would be no appropriate reference point to use to judge whether the risks to consumers (human or otherwise) of the genetically manipulated plant would greater than the original plant.

A further problem presents itself in that the Natural Product composition of a plant varies significantly depending on the challenges that the plant has experienced or is experiencing. Temperature, water, insect infestation, fungus infection, vertebrate grazing and bacterial infection are some of the more common factors that can change the Natural Product composition of a plant. Consequently, any analysis that is undertaken of the Natural Product composition of a plant really only applies to the 
conditions used and a number of studies of the composition of plants grown under a range of conditions, with and without infestations and infections, would be required to provide meaningful conclusions.

Thus the value of metabolomics would currently appear to be greater as a research tool than as a universal tool to help assess the risks presented to humans or other organisms through the widespread cultivation of a plant with a dramatically changed of Natural Product composition.

\section{Conclusion}

The Screening Hypothesis was based on the simple idea that potent, specific biological activity is a very rare property for a chemical to possess. The hypothesis predicted that evolution would have favoured plants and microbes that possessed metabolic traits that enhanced the production and retention of Natural Product diversity. Most of the traits predicted 15 years ago have been found. Hence the model has, so far, had a reasonable predictive value. The hypothesis predicted that these same traits would make the manipulation of pathways leading to Natural Products unpredictable. However, even if the genetic manipulation of an organism does cause it to produce some unexpected new products, the Screening Hypothesis suggests that these new chemicals have a very low probability of harming most consumers. Even if the new chemicals do possess some biomolecular activity that would be potentially harmful to the consumers, all consumers of Natural Products will have evolved generic methods of keeping the concentration of all ingested Natural Products low. In humans this generic protection against Natural Product accumulation must protect us efficiently from the thousands of Natural Products that a human might encounter in a modern, very varied, and often highly spiced diet.

Thus the Screening Hypothesis predicts that the manipulation of the Natural Product composition of plants will produce unknown outcomes but there is only a low probability of harm to human consumers. However, will the public be reassured by what in effect is a probability argument? I would suggest that there is a high probability that they will not.

\section{Acknowledgements}

I would like to thank Clive Jones (Institute for Ecosystem Studies, Milbrook, New York), who developed the concept of the Screening Hypothesis with me and has tried to give coherence to some of my thoughts.

\section{References}

1. Jensen RA (1976): Enzyme recruitment in evolution of new function. Annual Review of Microbiology 30: 409-425.

2. Chapman DJ, Ragan MA (1980): Evolution of Biochemical Pathways; Evidence from Comparative Biochemistry. Ann. Rev. Plant Physiol. 31: 639-678. 
3. Hochachka PW, Somero GN (1984): Biochemical Adaptation. Princeton, Princeton University Press. pp 537.

4. Firn RD, Jones CG (2000): The evolution of secondary metabolism - a unifying model. Molecular Microbiology 37: 989-994.

5. Firn RD, Jones CG (1996): An explanation of secondary product 'redundancy. In Recent Advances in Phytochemistry. Romeo et al. (eds). New York: Plenum Press: 295-312.

6. Jones CG, Firn RD (1991): On the evolution of secondary plant chemical diversity. Phil Trans Roy Soc B 333: 273-280.

7. Pogson B, et al. (1996): Arabidopsis carotenoid mutants demonstrate that lutein is not essential for photosynthesis in higher plants. Plant Cell 8: 1627-1639.

8. McConn M, Browse J (1996): The critical requirement for linolenic acid is pollen development, not photosynthesis, in an Arabidopsis mutant. Plant Cell 8: 403-416.

9. Jenks MA, et al. (1995): Leaf Epicuticular Waxes of the Eceriferum Mutants in Arabidopsis Plant Physiology 108: 369-377.

10. Exton JH (1994): Messenger molecules derived from membrane lipids. Curr. Opin. Cell Biol. 6: 226-229.

11. Smith WL, et al. (1991): in Biochemistry of Lipids, Lipoproteins and Membranes. Vane, D.E and Vane, J. (eds). New York, Elsevier: 297-325.

12. Vick \& Zimmerman (1984): The biosynthesis of jasmonic acid by several plant species. Plant Physiology 75: 458.

13. Zeevaart JAD, et al. (1991): Metabolism of $A B A$ and its physiological implications. In Abscisic Acid, Davies, W.D and Jones, H.G. (eds), Oxford. Bios Scientific.: 39-51.

14. Bu'Lock JD (1973): Comparative and functional aspects of the isoprene pathway in fungi. Pure Applied Chemistry 34: 435-461.

15. Boller T (1995): Chemoreception of microbial signals by plant cells. Annual Review of Plant Physiology and Plant Molecular Biology 46: 189-214.

16. Horowitz NH (1945): On the evolution of bichemical syntheses. PNAS 31: 153-157.

17. Kaufman SA (1993): The Origins of Order - Self Organisation and Selection in Evolution. New York; OUP. pp709.

18. Mann J (1987): Secondary metabolism. Oxford, Oxford University Press. pp. 374.

19. Kutchan T (2005): Update. Trends in Biotechnology, August 2005.

20. Kristensen C, Morant M, Ollsen CE, Ekstrøm CT, Galbraith DW, Møller BL, Bak S (2005): Metabolic engineering of dhurrin in transgenetic Arabidopsis plants with marginal inadvertent effects on metabolome and transcriptome. PNAS 102: 1779-1784.

21. Jørgensen K, Rasmussen AV, Morant M, Nielsen AH, Bjarnholt N, Zagrobelny M, Bak S, Møller BL (2005): Metabolom formation and the metabolic channeling in the biosynthesis of natural products. Current Opinion in Plant Science 8: 280291.

22. Firn RD, Jones CG (1999): Secondary metabolism and GMOs. Nature 400: 13-14.

23. Firn RD, Jones CG (2003): Natural Products - a simple model to explain chemical diversity. Natural Products Reports, 20, 382-391. 


\section{Gilles-Eric Seralini: Genome Fluidity and Health Risks for GMOs}

The Committee for Independent Research and Information on Genetic Engineering (CRII-GEN; www.crii-gen.org) is in favour of well-controlled genetic engineering and for an independent analysis of the assessment of GMOs, which shall be publicly accessible. However, CRII-GEN opines that more tests on environment and health (especially mammals) before deliberate release are necessary. The goal of CRII-GEN is to be independent from GMO producers an to provide independent expertise and evaluation of the GMOs' development.

\section{Genome fluidity}

There is an emergent knowledge on genome fluidity, which is due to the structure of DNA itself. DNA is never naked but dressed with proteins and chemical residues either natural or pollutants. It is important to note that this assembly pattern can be given over to progenies. There are only a few percent of active genes in a cell that are forming networks, which are very sensitive to the environment. They are corresponding with non-condensed DNA. (Most of the DNA is condensed and not available for exchanges in the cell.) This is the reason why mutations do not randomly occur in the genome. 18 levels of regulation of gene expression are known underlying the new complexity of genome regulation. Recently discovered gene regulation functions via interfering RNAs and micro-RNAs.

Other interesting phenomena proofing genome fluidity are gene hitch-hiking or gene amplification. Gene hitch-hiking describes a new process: If a gene is physically be linked to another, they will both co-evolve. Gene amplification can occur in response to biopollutans, e.g. genes for detoxification can be amplified in order to better comply with an toxic agent.

Also reverse transcription and mobile elements make up the genome fluidity. Mobile elements are small pieces of DNA that can move and/or duplicate within a genome. They resemble endogenous viruses or viruses ancestors and they are in part responsible of genome evolution, genetic diseases or arising of new species in rare cases, which was demonstrated in flower plants. They may help to form gene networks like Alu sequences in humans (short sequences of DNA that are dispersed throughout the genome). They can be compared to some extent only with artificial transgenes, that are small species of DNA that can move and duplicate in a genome. Mobile elements have been shown to take very big RNA pieces coming from non-coding regions that form networks and bring together non-condensed genes close to an open window of the nucleus in order to exchange with the environment. So there are really active networks between the genes. In the human genome, there are 40 to $45 \%$ of mobile elements, which is a lot. They do not work all at the same time, they do not all move at a time. In maize, where the mobile elements where discovered by Barbara McClintock, 
they make up $60 \%$ of the genome. We do not know their physiology but of course they are the fundamentals of what I call "ecogenetics", showing that the nucleus is an ecosystem, the ecosystem of genes.

What differentiate us most from monkeys, at the genetic level, is not in genes. At the DNA level, there are only about $1.3 \%$ differences between humans and some primates. Moreover, our genes form solely 5 - $10 \%$ of our DNA. But for instance $10 \%$ of our genome is composed of mobile Alu sequences (transposons). That is three times more than in chimpanzees. Thus, the major quantitative difference between human and monkeys lays in gene networks and regulations.

\section{Methods for transformation and GMO characterisation}

The GMOs can be compared to puzzles because the mixtures of little pieces of DNA come from different species. Moreover, most of the present GMOs have a viral and non-precise regulation. The synthetic genetic constructions is forced to enter a cell nucleus in a random way. The DNA is transferred by micro-injection, transfection, electroporation or biolistically, as for plants mostly by transfection or biolistically. This artificial DNS is inserted by chance in an unknown genome. In the genome complexity, to force one or several little pieces of DNA (the transgenes) to enter anywhere like it is done for GMOs corresponds to throw a screw in an engine to try to fix it. (We do that less precisely than transposons do!) As consequences, insertional mutagenesis of the transgene, by which the arrival in functioning gene networks are meant, gene networks disruption and unintended effects like gene silencing, illegitimate gene behaviour or recombinations can occur. In many times not only one but several copies enter the genome, e.g. in the first commercialised GMOs in Europe. For instance in the GM maize Bt 176, which contains five to six entire pieces of the transgenic DNA that each contains an antibiotic marker gene etc. Thus, the procedure is not precise.

After the successful insertion of the artificial sequences inside the genome and the regeneration of a whole plant, the parental GMO is bred with several interesting lines in order to commercialise several varieties out of a parental GMO. The classical breeding is needed because the transgene is not the only interesting trait. This means that cross hybridization is done at least five to six years. It is necessary to perform the breeding in the country where the GMO will be commercialised, because of the local specificity of the varieties transformed.

\section{Risk assessment of GMOs}

For the American hypothesis, genetic engineering is recognized to have an equivalent risk to classical hybridization. Then the compositional analysis and minor environmental trials on risks are sufficient and no traceability is needed. Long-term animal feedings trials are also not necessary.

By contrast, the European position can be described as is there more risk for genetic engineering than with classical breeding? "We don't know", "maybe" or "yes"; we don't 
say "no" a priori. This drives us to further analyses and labelling. Not only Europe but also 100 countries took this position of traceability at least during exchange at the borders. We have thus signed the so-called "Carthagena" international protocol. So, how can some people say GMOs are a big progress if they don't know where these are in our dishes, and what they do in our fields? We had the political force to implement labelling but we do not have the political force to oblige a real list of necessary tests in order to assess the health risks.

In the reductionist theory, the concept of substantial equivalence was applied forming the basis for the evaluation strategy of new food and feed. The principle of the substantial equivalence is to compare the new food and feed to a "reference" product. But this poses a problem because the traditional product of reference - the food traditionally eaten without known undesirable effect if eaten without excess - is highly variable not only because of genetic variability and additional environmental effects but also because of post-harvest treatments or a different potential mode of use of the new product. The comparison usually comprises the nutrients, toxic or anti-nutrients factors. However, detailed components to measure are not specified in the law. The food chemical analysis covers proteins, lipids, sugars, metals, but not e.g. individual herbicides or insecticide metabolites for example.

Another requirement is the characterization of the inserted DNA before insertion, the source, sequence, known function measurement of gene product and agronomic characteristics. However, the characterisation of the transgene after the insertion is absolutely necessary, as the results of the working group of Yves Bertheau from the European network of GMO laboratories shows. They have sequenced the transgenes after the insertion in all commercialized GMOs. In the GM maize T25 that is resistant to the herbicide LibertylinkTM, compared to the information on the construct, a certain sequence is missing. In MON 810, there is not the whole construct successfully inserted as well. For the $\mathrm{Bt} 176$, the differences are even more drastic as three rearranged fragments were detected. The first fragment of $118 \mathrm{bp}$ was homologous to P35S and T35S. The second contains a fragment of P35S and an unknown sequence of $215 \mathrm{bp}$, the third contains P35S and the bla gene (deletion of T35S). For construct 2 at least three integration sites were detected.

For geneticists, this would be sufficient to remove the authorization because it does not correspond to the molecule that was described. For drug e.g. this would remove the patent. For any reasons this does not apply for genetic engineering. Now, it remains unclear whether the differences observed are due to genome fluidity or whether this is due to insufficient characterization after the first transformation. However, gene sequencing after insertion of the transgene is still not an obligatory step in the GMO's commercial files.

\section{GMOs health risks}

For the health risks, two reasons can be discussed. A general risk might arise from the technique if the transformation generate a new metabolism disruption non visible when 
studying substantial equivalence. As for the American position, this risk is not higher than the classical hybridization. In Europe, labelling is required.

Another risk is linked to specific pesticide residues in GM food. And this risk is clearly underestimated. $99 \%$ of the GM corps are made to contain pesticides but they are not assessed like pesticides. Even if the risk assessment for pesticides is improved (endocrine disruption, nervous impact, allergenicity, bioaccumulation, combined effects, delayed or long-term effects ...), in the plant, there are new pesticide residues and possibilities of accumulation of residues because of the pesticide tolerance. $99.9 \%$ of commercialized GMOs are plants designed to contain pesticides that they absorb and/or produce: the so-called pesticide-plants. This is not going to change rapidly. New characteristics are not to be expected that would reach a significant percentage in the worldwide agriculture. For the Bt maize to fight against this larvae, there is a production of one kilogram per hectare. This amount have to be taken into account in the discussion on the reduction of pesticide. In Bt 176 the gene coding for the Bt toxin is modified to $44 \%$ in the GM plant, thus the toxin shall be assessed as a new drug. The only difference with pesticides is that GMOs are living organisms and they are not well assessed.

As for animal feeding tests, 54 references were available by the end of 2000. 31 are abstracts, websites and unavailable meeting reports. Two references are in press and 21 have been published in peer-reviewed journals. Therefrom, seven used rats (maximum duration 28 days for four of them), nine have been performed on chicken that do not go over 42 days. Four used pigs but only one test was published, which had fed an experimental maize. Two references fed cows of more than 42 days with Bt 176 maize that is not used anymore. Today there are no subchronic toxicity tests on rats that are obligatory. For new or pending GMOs there are only chronic toxicity tests for 90 days and not more.

In tests performed by Monsanto, 50 significant differences were noticed in rats eating the GM maize NK603 during 90 days. These differences have been judged "not important" with bizarre explanations by two scientists from a governmental commission. Other differences were found in similar experiments with GM oilseed rape GT73 on livers that showed an increase in weight up to $20 \%$ and kidneys of rats. These differences were kept confidential in the commercial files. We only got access after actions in Court.

For the GM maize MON 863, a 90 days feeding test was carried out. A significant increase of white blood cells have been detected as well as a higher level of lymphocytes in males, a decrease of reticulocytes (young red cells) in females and significant increase of blood sugar in females and elevated frequency of abnormal organ parameters (inflammation, regeneration...) in male kidney. But the French Commission did not accept to ask to repeat this tests and to make longer tests for economical reasons. Also the European Food Safety Authority accepted the tests as such for unknown reasons. 
The limits of the assessment today are: Pesticides are active principles dissolved in stabilizers and detergents when not commercialized in GMOs, and these are chosen and developed for their toxic effects on some levels of the ecosystem. (They are the only substances to be spread in the environment and to be toxic with intention in a warfree situation.) On mammals, they are tested during three months on three species, during one year on one species and as a life-long test during two years on another species, generally rat. Long-term effects are neglected as well as reproduction, endocrine or nervous impacts for instance. For Roundup, we have shown that it is able to kill placental cells within 18 hours on a higher extent than Glyphosate, the active compound alone (Richard et al. 2005).

Obviously, GMOs are less tested than pesticides on health. Although GMOs are designed to contain new pesticides (new herbicide metabolites or new insecticides), they are believed to be well-tested. But they are not. The 90 days tests for rats are not obligatory and not performed for all GMOs, but are the longest ones. Thus, there is big room for improvement. This is not due to science but to lobbying of GMO companies. The companies say a seed cannot be evaluated like a chemical, as this technology would not be profitable any more because seeds do not give the profit of a drug.

\section{Conclusions}

The directive CE 2001/18 is the best of the world on the paper. The black boxes to study with in vitro or in vivo tests are there. Bioaccumulation, combined and long term effects are unknown and studies at these levels have still to be encouraged. That is why we need a traceability and labelling. So I pospose the following actions: To apply an appendix to Dir 2001/18 and 1829/2003, asking for obligatory 90 days feeding tests - like for Dir 91/414/EEC for pesticides, which demands tests on three mammalian species in lab for 90 days and testing on one species for one year and on another species for two years. The second action is to ask for labelling of products from animals that were fed with GMOs because pesticide residues associated to GMOs may bioaccumulate in the food chain, especially Roundup residues and adjuvants, and because animals may have metabolic disorders when they eat GMOs.

Richard S, Moslemi S, Sipahutar H, Benachour N and Seralini GE (2005): Differential Effects of Glyphosate and Roundup on Human Placental Cells and Aromatase. Environ. Health Perspect. 113 (6), 716-20. 


\section{Arpad Pusztai: Facts behind the GM pea controversy}

\section{Introduction}

TJV Higgins and Maarten J Chrispeels developed a genetically modified (GM) pea (Pisum sativum) line in the CSIRO laboratory in Australia, expressing the gene of $\alpha$ amylase inhibitor ( $\alpha \mathrm{Al}$ ) from kidney bean (Phaseolus vulgaris cv. "Tendergreen"). They approached us at the Rowett in 1997 to carry out preliminary rat feeding studies with their GM pea to establish its nutritional value in comparison with its parent non-GM pea line. The study was duly done in 1998 and its results were published in the following year in The Journal of Nutrition. ${ }^{1}$

\section{Results of the 1999 study ${ }^{1}$}

\section{Compositional analysis:}

As customary before feeding studies, the GM-line, F-10 and non-GM, "Greenfeast" pea samples were subjected to a thorough chemical analysis before diets could be formulated. The Nitrogen and crude protein contents of the two lines were similar. The Greenfeast-line of non-GM peas contained $223 \mathrm{~g}$ protein $/ \mathrm{kg}$ seed meal and the F-10 GM-line $230 \mathrm{~g}$ protein/kg seed meal. However, there were a number of compositional differences between the transgenic- and parent-line peas. Thus, the trypsin inhibitor (TI) and lectin contents of all GM pea cultivars were substantially higher (lectin contents were up by $4 \mathrm{x}$ and $\mathrm{TI}$ by $2 \mathrm{x}$ ) than those in Greenfeast. The aAl content of the $\mathrm{F}-10$ line of $\mathrm{GM}$ peas was high; $3 \mathrm{~g} \alpha \mathrm{Al} / \mathrm{kg}$ seed meal. However, the bean and pea $\alpha \mathrm{Al}$ components had different subunit structures and glycosylation. Moreover, the bean $\alpha \mathrm{Al}$ was shown to be highly resistant to gut proteolysis while the pea aAl was quickly broken down in vivo in the rat gut

\section{Nutritional study:}

The nutritional study of GM-line F-10 was carried out by a design similar to that of our previous feeding studies, the details of which are amply described in the Journal of Nutrition paper1. The pea meals have been tested at two dietary inclusion levels of 300 $\mathrm{g} / \mathrm{kg}$ and $650 \mathrm{~g} / \mathrm{kg}$, respectively. The controls for comparison contained not only the Greenfeast pea-line at the same inclusion level as the GM peas but, to take into account of the expression of $\alpha \mathrm{Al}$ in the GM peas, two additional parental line pea group controls were also included in the study in which the non-GM peas were supplemented with 0.9 - and $2.0 \mathrm{~g} \mathrm{\alpha Al} / \mathrm{kg}$ diet, respectively, corresponding to the amounts of $\alpha \mathrm{Al}$ in the two GM pea test groups. All diets were iso-proteinic and iso-energetic and fully supplemented with vitamins and minerals.

Young, rapidly growing rats (four rats per group) closely matched for weight, $83.3 \mathrm{~g}$ (SD 1g) were pair-fed with the diets for 10 days. Although the results were similar for all 
groups there were also a number of significant nutritional differences between the rats fed diets containing transgenic-, or non-transgenic peas. Thus, rats on transgenic pea $(30 \%)$ diet had higher faecal output, faecal- and urine $\mathrm{N}$ loss, slightly reduced body $\mathrm{N}$ and water retention and therefore transgenic-peas had a slightly lower nutritional value than non-transgenic peas.

At the completion of the experiment the rats were dissected and their tissues weighed. Quite importantly, particularly in retrospect of the somewhat similar results of our later and more detailed studies with GM potatoes expressing the snowdrop (Galanthus nivalis) bulb lectin gene, the small intestine and large bowel (caecum) of rats fed on transgenic pea diet was significantly enlarged in comparison with that of rats fed on non-transgenic pea diet. Unfortunately, in this preliminary study there were no histology or immune studies!

\section{Conclusions:}

Despite of these relatively small nutritional differences between the transgenic-, and the non-transgenic peas a cautious optimism was expressed in the paper that as the $\alpha \mathrm{Al}$ in GM peas was quickly degraded in the rat gut, it may be possible to include it in commercial animal rations at a low inclusion level, providing that the effect on the animals was closely monitored. However, no human use could be contemplated without first carrying out specific human risk assessment.

\section{Results of the 2005 study ${ }^{2}$}

\section{Compositional differences:}

Unfortunately, no compositional analysis data of any sort were given and no TI and lectin contents reported. Indeed, as there was no reference to the 1999 paper in the 2005 study, it is uncertain whether they used the same F-10 GM-line as before. However, the glycosylation and subunit structure of bean ("Tendergreen" or Pinto) and GM pea-expressed aAl were examined in detail by western-immunoblot analysis and MALDI-TOF-MS. The authors have come to the conclusion that $\alpha A I$ components in the two bean cultivars were identical or very similar but that they were different from the GM pea $\alpha A I$, even though that a closer inspection of the data of the MALDI-TOF-MS revealed that the $\mathrm{aAl}$ components in the two bean varieties were quite different. This difference was neatly confirmed in the 2005 study by showing that priming with Pinto bean feeding followed by Tendergreen $\alpha \mathrm{Al}$ challenge resulted in no $\alpha \mathrm{Al}$-specific serum $\operatorname{lgG}$ or increased mucus-secreting- or eosinophil lung cells (Figure $2^{2}$ ). Therefore the use of Pinto beans as controls instead of Tendergreen (from which the gene of aAl was transferred into peas) in the 2005 study was not justified and also a scientific mistake.

\section{Nutritional study:}

No information in the paper was given about the mice feeding protocol. 


\section{Immunological consequences}

The 2005 study revealed major immunological differences in mice that had been fed on beans or peas and consequently challenged with $\alpha \mathrm{Al}$ from $\mathrm{GM}$ peas or from Tendergreen beans. However, none of the immune aAl challenges were done intragastricly but in tissues that have low or no proteolytic activity. Therefore it is not known whether the transgenic $\alpha \mathrm{Al}$ in $\mathrm{GM}$ peas was prone to proteolytic breakdown in the mouse gastrointestinal tract as was established for rats ${ }^{1}$. This omission is rather curious in view that the gastrointestinal (as opposed to lung- or footpad-) stability of a food or feed ought to be of paramount importance in any risk assessment.

The main conclusions of the 2005 study were:

- Pinto bean consumption and respiratory challenge with Tendergreen bean $\alpha \mathrm{Al}$ caused no inflammation

- GM pea consumption led to the development of aAl-specific IgG and footpad challenge of the transgenic pea-fed mice (but not the conventional pea-fed mice) with purified transgenic pea $\alpha \mathrm{Al}$ led to a significant DTH (delayed type hypersensitivity) response

- Transgenic pea-feeding (but not feeding with conventional pea) primed mice and when challenged with pea $\alpha \mathrm{Al}$ elicited a CD4+ Th2 cell-mediated inflammation and the production of IL-4 and IL-5

- Concomitant exposure of the gut to transgenic $\alpha \mathrm{Al}$, but not to bean $\alpha \mathrm{Al}$ and heterogeneous food antigens cross-primes and elicits immunogenicity for poorly immunogenic food antigens.

\section{Conclusions of the 2005 paper:}

The transgenic transfer of a protein gene from a donor plant species even to a closely related species may lead to the synthesis of structural variants possessing altered immunogenicity and therefore in the light of these findings it is possible that other GM crops may also develop similarly altered immune behaviour.

\section{My final conclusions}

Conclusions of our work in 1999 that bean and GM pea aAls were different were confirmed by analytical and immune studies in the 2005 paper. It is therefore quite possible, as stated in the published paper, that these structural differences were most likely to be mainly or partly responsible for the altered immunogenicity of the pea $\alpha \mathrm{Al}$. However, some of the essential controls were omitted and results obtained with other controls were wrongly interpreted in the paper. Thus, the differences between Pinto and Tendergreen are not confined to the lack of a lectin in the Pinto beans. Indeed the lectin in Pinto beans is different from that in Tendergreen beans, in addition to the clear difference between the respective aAl components of the two bean varieties. There is also nothing interesting in the finding that when non-GM peas were fed to mice and 
then challenged with transgenic pea $\alpha \mathrm{Al}$, no immune response was obtained, as nonGM peas are devoid of $\alpha A I$ (Figure $3 A$ and $3 B^{2}$ ). Similarly, GM chickpea feeding could not have primed mice for a successful GM pea aAl immune challenge because although the source of the aAl gene (from Tendergreen beans) was the same for both GM peas and GM chickpeas, protein glycosylation in peas, beans and chickpeas proceeds differently and therefore these three $\alpha \mathrm{Al}$ components were different. The only firmly established conclusion in the paper was that priming with GM pea feeding followed by $\alpha \mathrm{Al}$ isolated from the GM peas elicited an immune response. However, on the basis of the evidence presented, the possibility cannot be ruled out that as a result of the genetic manipulation other unpredicted compositional changes could have also made a contribution to the overall effects. However, this will not detract from the significance of the findings in the 2005 paper. In view of these, all other presently accepted or to be approved GM crops must be subjected to a similar immune testing protocol, including all the controls omitted in the 2005 paper, to establish whether they are safe or not. Till this is done we must declare a moratorium on the release and growing of GM crops.

\section{References:}

1. Pusztai A, Grant G, Bardocz S, Alonso R, Chrispeels MJ, Schroeder HE, Tabe LM and Higgins TJV (1999): Expression of the insecticidal bean $\alpha$-amylase inhibitor transgene has minimal detrimental effect on the nutritional value of peas fed to rats at $30 \%$ of the diet. J. Nutr. 129, 1597-1603.

2. Prescott VA, Campbell PM, Moore A, Mattes J, Rothenberg ME, Foster PS, Higgins TJV and Hogan SP (2005): Transgenic expression of bean a-amylase inhibitor in peas results in altered structure and immunogenicity. J.Agric. Food Chem., 53, 9023-9030.

3. Pusztai A, Grant G and Stewart JC (1981): A new type of Phaseolus vulgaris (cv. Pinto III) seed lectin: isolation and characterization. Biochim. Biophys. Acta, 671, 146154. 


\section{Irina Ermakova: Influence of genetically modified soya on the birth-weight and survival of rat pups}

\section{Introduction}

Four main sources of the hazards of GMO are discussed by scientists worldwide: 1) those due to the new genes, and gene products introduced; 2) unintended effects inherent to the technology; 3 ) interactions between foreign genes and host genes; and 4) those arising from the spread of the introduced genes by ordinary cross-pollination as well as by horizontal gene transfer (World Scientists' Statement 2000). GM crops contain material, which is not present in them under natural conditions, and they form a part of our daily diet. To understand what effect they can have on us and on our animals it is vitally important to study the influence of these GM plants in different organisms for several generations. At the present, these studies are lacking from the scientific literature. Several detrimental effects of GM crops had been showed on the metabolism of animals. The hazard of genetically modified organisms (GMO) was shown for animals and the environment in many investigations (Traavik 1995; Ho and Tappeser 1997; Pusztai 1999 and 2001; Kuznetcov et al. 2004 and others). Experiments, conducted by Pusztai showed that potatoes modified by the insertion of the gene of the snowdrop lectin (an insecticidal proteins), stunted the growth of rats, significantly affected some of their vital organs, including the kidneys, thymus, gastrocnemius muscle and others (1998) and damaged their intestines and their immune system (Ewen and Pusztai 1999). Similar effect of GM potatoes on rats was obtained at Institute of Nutrition in Russia (Ermakova 2005). In the researches of Malatesta with co-authors the significant modifications in the cells of liver, exocrine pancreas and testis of mice, fed by diet containing Roundup Ready GM soybean were described (Malatesta et al. 2002, 2003; Vecchio et al. 2004).

It is put forward in the risk assessment documents that the GM components of transformed plants are completely destroyed in the digestive tract of humans and animals, together with the other genetic material found in them. However foreign DNA plasmids are steadier against the digestion, than it was originally believed. Plasmid DNA and GM DNA were found in microorganisms of the intestine and in saliva (Mercer et al. 1998; Coghlan 2002). Experimental researches in mice showed that ingested foreign DNA can persist in fragmented form in the gastrointestinal tract, penetrate the intestinal wall, and reach the nuclei of leukocytes, spleen and liver cells (Schubbert et al. 1994). In another research of Schubbert et al. (1998) the plasmid containing the gene for the green fluorescent protein ( $p E$ EFP-C1) or bacteriophage M13 DNA were fed to pregnant mice. Foreign DNA, orally ingested by pregnant mice, was discovered in blood (leukocytes), spleen, liver, heart, brain, testes and other organs of foetuses and newborn animals. The authors considered that maternally ingested foreign DNA could be potential mutagens for the developing fetus. At the same time Brake and 
Evenson (2004) analyzing the testis in mice as a sensitive biomonitor of potential toxic, didn't find negative effects of transgenic soybean diet on fetal, postnatal, pubertal or adult testicular development.

There is a lack of investigations on the influence of GM crops on mammals, especially on their reproductive function. Therefore, we decided to undertake a study to see the effect of the most commonly used GM crop on the birth rate, mortality and weight gain of rat pups, if the females were fed diets supplemented with Roundup Ready soya.

\section{Materials and Methods}

\section{Diets and dietary components:}

Roundup-Ready (RR) soya (40.3.2 line) was used in experiments. Since we had no access to the exact parent line, we bought a traditional (trad.) soya variety (Arcon SJ 91-330, ADM, the Netherlands), which had a similar composition and nutritional value to the RR soya.

The soya flour was prepared from these varieties by grinding the raw whole soya bean seeds mix with water $(40 \mathrm{ml})$ to form a paste. Standard laboratory food was obtained from Moscow, Russia.

\section{Animals:}

Wistar rats from (Stolbovay, Russia) were used in the experiment. The animals were brought up to sexual maturity on laboratory rat feed. When their weight reached about 180 - $200 \mathrm{~g}$, the female rats were divided into 3 groups, and housed in groups (3 rat/cage), and kept under normal laboratory conditions.

The feeding scheme was as follows. Females in every cage daily received dry pellets from a special container placed on the top of their cage. Those rats receiving soya flour supplement, were given the soya flour in a small container placed inside their cage ( $20 \mathrm{~g}$ x $40 \mathrm{ml}$ water) for three rats and, so $5-7 \mathrm{~g}$ flour for each rat every day.

\section{Experimental protocol:}

One group of female rats of $180-200 \mathrm{~g}$ weight was allocated to the experimental group, and received flour/rat/day prepared from Roundup-Ready soya, added to the rat feed for two weeks. Another group females were allocated to the control group, but their diet was supplemented with the same amount of soya flour, prepared from the trad. soya. We also introduced a positive control group, which had not been exposed to soya flour. Therefore females have only got the standard laboratory feed without any supplementation, although it is acknowledged that the energy and protein content of this diet was less than in the other two groups. After two weeks on the diets all groups of 3 females were mated with two healthy males of the same age, who have never been exposed to soya flour supplements. First one than the other male was put into the cage for 3 days. In order to avoid infection of females, the sperm count and quality has not been determined. We carried on with feeding the respective diets to all females 
during mating and pregnancy. Upon delivery, all females were transferred to individual cages, and the amount of soya supplement was increased by an additional $g$ for every pup born. Lab feed and water was available for all animals ad libitum during the experimental period. When rat pups opened their eyes and could feed themselves (from 13-14 days of age), the daily dose of soya supplement was increased till $2-3 \mathrm{~g}$ for every pup, although all rats had free approach to the soya. All rats ate their soya portions well. After finishing of experiments organs of some pups were taken out and weighed.

\section{Statistical analysis:}

The level of mortality was analyzed by the one-way ANOVA, using of Newman-Keuls test for share distribution. The pup's weight and its distribution were checked by MannWhitney test and Chi-square in StatSoft Statistica v6.0 Multilingua (Russia).

\section{Results}

Quantitative analysis of RR soya by using the "CP4-LEC-RT-PCR" construct confirmed the presence of genetic modification in $100 \%$ of the flour. In the traditional, non-GM soya flour only traces $(0.08+0.04 \%)$ of the same construct was present, most likely resulting from cross-contamination.

By the end of the experiment, from the 15 females included in the experiment, 11 gave birth and produced a total of 122 rat pups. The 4 rats who became pregnant from 6 females on the positive control diet gave birth to 44 pups (an average of 11 pups/female), while the four females, from the six on GM soya flour supplemented groups gave birth to 45 (11.3 pups/female), and 3 from traditional soya group - 33 pups (11 pups/female).

Supplementation of the diet of the females with GM soya led to the death of 25 pups, out of the 45 born by the end of the third week of lactation, while during the same period on the traditional soya supplemented diets only 3 pups died from 33 . The mortality in the positive control group was also 3 , but from the larger number of pups born, as it seen in Table 1.

High pup mortality was generally characteristic for females fed the GM soya flour (Table 2).

Among the pups from the females fed the positive control diet, 2 pups died during the first week, and 1 during the second week after delivery. All pups from females fed traditional soya flour died during the first week after birth. However, pups from females fed the GM soya flour supplemented diet kept dying during lactation period as it is evident from Table 3.

In two weeks after their birth the weight of pups (with SE) from the GM soya supplemented group was less $(23.95 \mathrm{~g} \pm 1.5 \mathrm{~g})$ than that of the pups of the positive control group $(30.03 \mathrm{~g} \pm 1.1 \mathrm{~g} ; \mathrm{p}<0.005)$, or from the traditional soya flour supplemented group $(27.1 \mathrm{~g} \pm 0.9 \mathrm{~g} ; \mathrm{p}<0.1)$. Since the number of surviving pups were so different, 
the weigh distribution of the pups were compared in Table 4. From the data it is evident, that $36 \%$ of the pups from the GM soya group weighed less than $20 \mathrm{~g}$, in comparison with the $6 \%$ in the positive control group, and with the $6.7 \%$ found in the traditional soya supplemented diet group (Table 4). Study of pup's organs mass showed that the organs of small pups from GM group were tiny in comparison with the same of other groups except the brain mass (Table 5). This fact indicated that the pups from the GM group were the same age as others, but changes were occurred with the development of internal organs. Slight negative effect was found in the group, which received the traditional soya, but this effect was not significant. No lethality of females and survived young pups eating the GM soya flour supplemented diet was observed.

\section{Discussion}

The reproductive behaviour of female rats fed on standard laboratory feed supplemented with soya flour prepared from either genetically modified (RR) or traditional soybean seeds was studied to see the effect of the diet on pregnancy, lactation and the growth of the rat pups. Since it is well established, that raw soybean contains a number of anti-nutrients (such as the lectins, trypsin inhibitors, etc. (Pusztai et al. 1998), and also female hormone-like substances, it was thought to be necessary to compare these data also with those from a positive control group when animals were not exposed to any soya flour supplementation.

In order to understand the mechanism how this widely consumed GM crop exerts its influence on the reproductive performance of mammals and their offspring, it would be necessary to perform complex researches, including histological, genetic and embryotoxicological investigations. However, we had to restrict our experiments only for a short time-span, and starting to feed the female rats two weeks before mating. However, unlike the experiments of Brake and Evenson (2004), who started to feed pregnant mice, in our experiments the diets supplemented with GM or traditional soya flours were already given to the female rats 2 weeks before mating already, and we continued to treat them with their respective diet until the pups were weaned.

Upon delivery, very unexpectedly a very high rate of pup mortality ( 55,6\%) was observed in among pups from females, whose diet was supplemented with the Roundup Ready soya flour in comparison with the pups of both the positive control $(6,8 \%)$ and the traditional soya flour supplemented (9\%) groups. Also, in this group the pups continued to die over the period of lactation, which occurred only in the GM soya fed group. At the same time, the weights of the surviving rat pups were also lower. It is the more surprising, since the pups were smaller, about half, therefore more milk should have been available for the individual pups. They should have a better chance to grow optimally, unless the amount, and/or the quality of the milk were not affected by consuming the GM soya flour.

Our data allow us to speculate and presume that the negative effect of GM soya on the newborn pups could be mediated by several possible factors. Firstly, it can be the result of transformation, and insertion of the foreign genes, which could enter into the 
sexual/stem cells, or/and into cells of the fetus, as it was observed by Schubbert et al. (1998). In their experiments the plasmid containing the green fluorescent protein (pEGFP-C1) gene, or the bacteriophage M13 DNA was fed to pregnant mice. The presence of the foreign DNA was detected in the cells of the mice in both cases. Also, the instability of gene constructs was described for GM-soya (Windels et al. 2001) and rice (Yang et al. 2005). Secondly, negative effect could be result of the highly mutagenic nature of the GM transformation process as illustrated by Wilson et al. (2005). Finally, the negative effect of GM soya could be mediated by the accumulation of Roundup residues in GM soya. However, no mortality was observed with female rats, nor with the young pups survived, although they also began to eat the GM soya, it was supposed that the effect could be mediated by the two first factors.

\section{References}

Brake DG and Evenson DP (2004): A generational study of glyphosate-tolerant soybeans on mouse fetal, postnatal, pubertal and adult testicular development. Food Chemistry and Toxicology 42: 29-36.

Coghlan A (2002): GM crop DNA found in human gut bugs. NewScientist. 2002.

Ermakova IV (2005): Conclusion to the report about feeding of rats by genetically modified potatoes Russet Burbank Agrarian Russia 2005: 62-64.

Ewen SW, Pusztai A (1999): Effect of diets containing genetically modified potatoes expressing Galanthus nivalis lectin on rat small intestine. Lancet 354 (9187).

Ho MW and Tappeser B (1997): Potential contributions of horizontal gene transfer to the transboundary movement of living modified organisms resulting from modern biotechnology. In Transboundary Movement of Living Modified Organisms Resulting from Modern Biotechnology: Issues and Opportunities for PolicyMakers (K.J. Mulongoy, ed.) International Academy of the Environment, Switzerland: 171-193.

Kuznetcov VV, Kulikov AM, Mitrohin IA and Cidendambaev VD (2004): Genetically modified organisms and biological safety. Ecos 2004: 3-64.

Malatesta M, Biggiogera M, Manuali E, Rocchi MBL, Baldelli B, Gazzanelli G (2003): Fine structural analyses of pancreatic acinar cell nuclei from mice fed on GM soybean. Eur. J. Histochem. 47: 385-388.

Malatesta M, Caporalony C, Gavaudan S, Rocchi MBL, Tiberi C, Gazzanelli G (2002): Ultrastructural, morphometrical and immunocytochemical analysis of hepatocyte nuclei from mice fed on genetically modified soybean. Cell Struct. Funct. 27: 173-180.

Mercer DK, Scott KP, Bruce-Johnson WA, Glover LA and Flint HJ (1999): Fate of free DNA and transformation of oral bacterium Streptococcus gordonii DL1 plasmid DNA in human saliva. Applied and Environmental Microbiology 65: 6-10.

Pusztai A (1998): Report of Project Coordinator on data produced at the Rowett Research Institute. SOAEFD flexible Fund Project RO 818. 22 October 1998.

Pusztai A (2001): Genetically Modified Foods: Are They a Risk to Human/Animal Health. Biotechnology: genetically modified organisms. 2001.

Schubbert R, Lettmann C and Doerfler W (1994): Ingested foreign (phage M13) DNA survives transiently in the gastrointestinal tract and enters the blood stream of mice. Molecules. Genes and Genetics 242. 495-504. 
Schubbert R, Hohlweg U, Renz D and Doerfler W (1998): On the fate of orally ingested foreign DNA in mice: chromosomal association and placental transmission in the fetus. Molecules. Genes and Genetics 259: 569-576.

Traavik T (1999): Too Early May Be Too Late. Ecological Risks Associated with the Use of Naked DNA as a Biological Tool for Research, Production and Therapy (Norwegian). Report for the Directorate for Nature Research Tungasletta 2, 7005 Trondheim. English translation, 1999.

Yang L, Ding J, Zhang C, Jia J, Weng H, Liu W, Zhang D (2005): Estimating the copy number of transgenes in transformed rice by real-time quantitative PCR. Plant Cell Rep. 23, 10-11: 759-763.

Vecchio L, Cisterna B, Malatesta M, Martin TE, Biggiogera B (2003): Ultrastructural analysis of testes from mice fed on genetically modified soybean. Eur. J. Histochem. 48: 449-453.

Wilson A, Latham J, Steinbrecher R (2004): Genome Scrambling - Myth or Reality? Transformation - Induced Mutations in Transgenic Crop Plants. EcoNexus, 2004, 35p.

Windels P, Taverniers I, Depicker A, Van Bockstaele E, De Loose M (2001): Characterisation of the Roundup Ready soybean insert. Eur. Food Res. Technol. 231: 107-112.

World Scientists Statement. Supplementary Information of the Hazards of Genetic Engineering Biotechnology. Third World Network. 2000.

\section{Acknowledgements:}

I am very thankful to Dr. Susan Pusztai and Dr. Arpad Pusztai for valuable remarks and comments.

Table 1: Mortality of rat pups by the end of the $3^{\text {rd }}$ week of lactation; *compared to the GM soya flour supplemented group

\begin{tabular}{|l|c|c|c|}
\hline Groups & Number of pups born & Number of dead pups & $\begin{array}{l}\text { Dead pups/total born } \\
(\%)\end{array}$ \\
\hline Positive control & 44 & $\begin{array}{c}3 \\
(p=0,000118)^{*}\end{array}$ & $6.8 \%$ \\
\hline Trad. Soya & 33 & $\begin{array}{c}3 \\
(p=0,000103)^{*}\end{array}$ & $9 \%$ \\
\hline GM soya & 45 & 25 & $55.6 \%$ \\
\hline
\end{tabular}


Table 2: Number rat pups died from the litter of individual females on the GM soya flour supplemented diet

\begin{tabular}{|l|c|c|c|}
\hline Females & $\begin{array}{l}\text { Number of newborn } \\
\text { rats }\end{array}$ & $\begin{array}{l}\text { Number of pups } \\
\text { died }\end{array}$ & $\begin{array}{l}\text { Number of dead } \\
\text { pups/born ( \%) }\end{array}$ \\
\hline Female No. 1 & 11 & 7 & $64 \%$ \\
\hline Female No. 2 & 8 & 4 & $50 \%$ \\
\hline Female No. 3 & 13 & 6 & $46 \%$ \\
\hline Female No. 4 & 13 & 8 & $62 \%$ \\
\hline
\end{tabular}

Table 3.The number of dead pups (number and as \%) from the treatment groups at different times after birth

\begin{tabular}{|l|c|c|c|}
\hline Groups & 1st week & 2nd week & 3rd week \\
\hline Positive control & $4.5 \%(2)$ & $2.3 \%(1)$ & 0 \\
\hline Trad. Soya & $9 \%(3)$ & 0 & 0 \\
\hline GM soya & $31,1 \%(14)$ & $13,4 \%(6)$ & $11,1 \%(5)$ \\
\hline
\end{tabular}

Table 4. Weigh distribution of rat pups by 2 weeks of age on different diets; * - in comparison with GM-group

\begin{tabular}{|l|c|c|c|c|}
\hline Group: & $\mathbf{5 0 - 4 0} \mathbf{g}$ & $\mathbf{4 0 - 3 0} \mathbf{g}$ & $\mathbf{3 0 - 2 0} \mathbf{g}$ & $\mathbf{2 0 - 1 0} \boldsymbol{g}$ \\
\hline Positive control & $12.5 \%$ & $37.5 \%$ & $44 \%$ & $6 \%{ }^{*}(\mathrm{p}<0.01)$ \\
\hline Trad. soya & $0 \%$ & $20 \%$ & $73.3 \%$ & $6.7 \%{ }^{*}(\mathrm{p}<0.05)$ \\
\hline GM soya & $0 \%$ & $23 \%$ & $41 \%$ & $36 \%$ \\
\hline
\end{tabular}

Table 5: Examples of absolute values of organ mass in pups in three weeks after their birth. Fixation in formaldehyde 0.1M PBS, pH7.2.

\begin{tabular}{|l|c|c|c|c|c|c|c|c|}
\hline NN & Body & Liver & Lungs & Heart & Kidneys & Spleen & Testes & Brain \\
\hline $\begin{array}{l}\text { N26; } \\
\text { control }\end{array}$ & 69 & 3.80 & 1.20 & 0.37 & $0.44 / 0.44$ & 0.52 & $0.34 / 0.34$ & $\mathbf{1 . 6 7}$ \\
\hline $\begin{array}{l}\text { N27; } \\
\text { control }\end{array}$ & 72 & 4.63 & 1.55 & 0.38 & $0.52 / 0.42$ & 0.81 & $0.3 / 0.3$ & $\mathbf{1 . 6}$ \\
\hline $\begin{array}{l}\text { N28; } \\
\text { GM soya }\end{array}$ & 35 & 1.83 & 0.6 & 0.19 & $0.28 / 0.28$ & 0.21 & $0.13 / 0.14$ & $\mathbf{1 . 6 0}$ \\
\hline $\begin{array}{l}\text { N29; } \\
\text { GM soya }\end{array}$ & 30 & 1.68 & 0.5 & 0.20 & $0.19 / 0.20$ & 0.19 & $0.14 / 0.18$ & $\mathbf{1 . 5 4}$ \\
\hline $\begin{array}{l}\text { N30; } \\
\text { trad. soya }\end{array}$ & 62 & 4.28 & 0.95 & 0.36 & $0.38 / 0.38$ & 0.24 & $0.22 / 0.26$ & $\mathbf{1 . 7 6}$ \\
\hline $\begin{array}{l}\text { N31; } \\
\text { trad. soya }\end{array}$ & 63 & 4.35 & 0.94 & 0.39 & $0.42 / 0.42$ & 0.32 & $0.22 / 0.23$ & $\mathbf{1 . 6 6}$ \\
\hline
\end{tabular}




\section{Manuela Malatesta: A diet based on genetically modified soybean affects cell functions in mice}

No direct evidence has so far been reported that genetically modified (GM) food may affect human or animal health; however, the scientific literature in this field consists of few heterogeneous reports concerning different potential risks, such as allergy, fate of transgenic DNA and proteins, toxic effects (e.g. 1-6,12). In particular, long-term studies on the possible effects on animals of a diet involving significant amounts of GM plants are quite scarce.

In fact, any possible - either direct or indirect, immediate or cumulative - consequence of the consumption of GM organisms should be taken into consideration to evaluate the safety of transgenic food.

In the light of this assumption, we decided to analyse the effects of a diet containing GM soybean on mouse cells and tissues; actually, mouse is a suitable and easy-tohandle experimental species with a relatively short lifespan which also allows to properly evaluate possible cumulative effects. A multidisciplinary approach was selected to evaluate the relationships between cell structural modifications and the resulting functional changes.

Pregnant Swiss mice were fed on a diet containing wheat, barley, maize, alfalfa, skimmed milk, minerals and $14 \%$ of a GM soybean (Roundup Ready, line 40-3-2) obtained by the insertion of the bacterial CP4 EPSPS gene (5-enolpyruvylshikimate-3phosphate synthase, from Agrobacterium sp. strain CP4) conferring tolerance to glyphosate, i.e. the active ingredient of the herbicide Roundup ${ }^{\circledR}$ (11). In parallel, control mice were fed on the same diet containing non-GM soybean. The litter were fed on the respective parental diet and the animals were killed at the age of $1,2,5,8,12$, 18 and 24 months. Several organs (e.g. liver, pancreas, intestine, kidney, bladder, testis, skeletal muscle) and body fluids (blood, urine) were collected: some samples were processed for morphological, cytochemical, and immunocytochemical analyses at light, confocal and electron microscopy, while other samples were immediately frozen in liquid nitrogen and kept at $-80^{\circ} \mathrm{C}$ for biochemical analyses.

Three different tissues have so far been analysed: 1) the liver, as the primary site for biotransformation of the digestion products, which also degrades and metabolises toxic compounds and exerts an important control over the general metabolism; 2) the exocrine pancreas, which is responsible for the synthesis, storage and regulated secretion of the digestive enzymes in the pancreatic juice; 3 ) the testis, which is generally considered as a reliable bio-indicator of diet-related alterations in cell proliferation and differentiation.

Our observations demonstrate significant modifications in hepatocytes of GM fed mice, where cell nuclei showed ultrastructural and molecular changes suggesting an increased metabolic rate, whereas no significant modification in cytoplasmic structures 
or in several enzyme activities was found (8). In pancreatic acinar cells of mice fed on GM soybean, the nuclear features indicated reduced post-transcriptional hnRNA processing and/or nuclear export; consistently, a decrease in zymogen synthesis and processing was also observed, although no alteration in the whole pancreatic gland function was detected $(7,9)$. In the testis, lower transcription and decreased content of splicing factors were observed in spermatogonia, spermatocytes and Sertoli cells of young GM fed mice, together with RER enlargements in Sertoli cells; however, at 8 months of age, the nuclear differences disappeared, likely due to internal compensatory mechanisms (13). Interestingly, recent experiments made on adult mice fed on GM soybean since their weaning and then submitted to a diet containing non transgenic soybean revealed that the GMO-related modifications in liver and pancreas are reversible. At the same time, control mice submitted for one month to a diet containing GM soybean underwent cellular modifications similar to those found in animals fed on GM soybean from their weaning (10).

These results further confirm the role of the GM food in the induction of morphofunctional modifications in mouse cells.

It is still to be established which could be the factor(s) in the GM soybean capable of inducing such modifications. Among the putative causes, it should be taken in consideration the possible presence of traces of Roundup, i.e. the herbicide to which the GM soybean was made resistant (both the active ingredient glyphosate or their metabolites or other additives in the herbicide could be responsible). In addition, it should be mentioned that GM soybean contains lower amounts of phytoestrogens, non-steroidal plant compounds influencing various cell activities by binding to oestrogen receptors. Investigations are in progress to answer this basic question.

\section{References:}

1. Bernstein JA, Bernstein IL, Bucchini L, Goldman LR, Hamilton RG, Lehrer S, Rubin C, Sampson HA (2003): Clinical and laboratory investigation of allergy to genetically modified foods. Environ. Health Perspect. 111: 1114-1121.

2. Duggan PS, Chambers PA, Heritage J, Forbes MJ (2003): Fate of genetically modified maize DNA in the oral cavity and rumen of sheep. Br. J. Nutr. 89: 159-166.

3. Ewen SW, Pusztai A (1999): Effect of diets containing genetically modified potatoes expressing Galanthus nivalis lectin on rat small intestine. Lancet 354:13531354.

4. Flachowsky G, Aulrich K (2003): Assessment of novel foods in animal nutrition. Forum Nutr. 56: 335-337.

5. Lack G (2002): Clinical risks assessment of GM foods. Toxicol. Lett. 127: 337-340.

6. Lutz B, Wiedemann S, Einspanier R, Mayer J, Albrecht C (2005): Degradation of Cry1Ab protein from genetically modified maize in the bovine gastrointestinal tract. J. Agric. Food Chem. 53: 1453-1456.

7. Malatesta M, Biggiogera M, Manuali E, Rocchi MBL, Baldelli B, Gazzanelli G (2003): Fine structural analyses of pancreatic acinar cell nuclei from mice fed on GM soybean. Eur. J. Histochem. 47: 385-388. 
8. Malatesta M, Caporaloni C, Gavaudan S, Rocchi MBL, Tiberi C, Gazzanelli G (2002): Ultrastructural morphometrical and immunocytochemical analyses of hepatocyte nuclei from mice fed on genetically modified soybean. Cell Struct. Funct. 27: 173-180.

9. Malatesta M, Caporaloni C, Rossi L, Battistelli S, Rocchi MBL, Tonucci F, Gazzanelli G (2002): Ultrastructural analysis of pancreatic acinar cells from mice fed on genetically modified soybean. J. Anat. 201: 409-416.

10. Malatesta M, Tiberi C, Baldelli B, Battistelli S, Manuali E, Biggiogera B (2005): Reversibility of hepatocyte nuclear modifications in mice fed on genetically modified soybean. Eur. J. Histochem. 49: 237-242.

11. Padgette SR, Kolacz KH, Delannay X, Re DB, LaVallee BJ, Tinius CN, Rhodes WK, Otero YI, Barry GF, Eichholtz DA, Peschke VM, Nida DL, Taylor NB and Kishore GM (1995): Development, identification and characterization of a glyphosatetolerant soybean line. Crop Sci. 35: 1451-1461.

12. Schubbert R, Hohlweg U, Renz D, Doerfler W (1998): On the fate of orally ingested foreign DNA in mice: chromosomal association and placental transmission to the fetus, Mol. Gen. Genet. 259: 569-576.

13. Vecchio L, Cisterna B, Malatesta M, Martin TE, Biggiogera B (2004): Ultrastructural analysis of testes from mice fed on genetically modified soybean. Eur. J. Histochem. 48: 449-453. 


\section{Beatrix Tappeser: A continuous challenge: Integration of state of the art knowledge into current risk assessment}
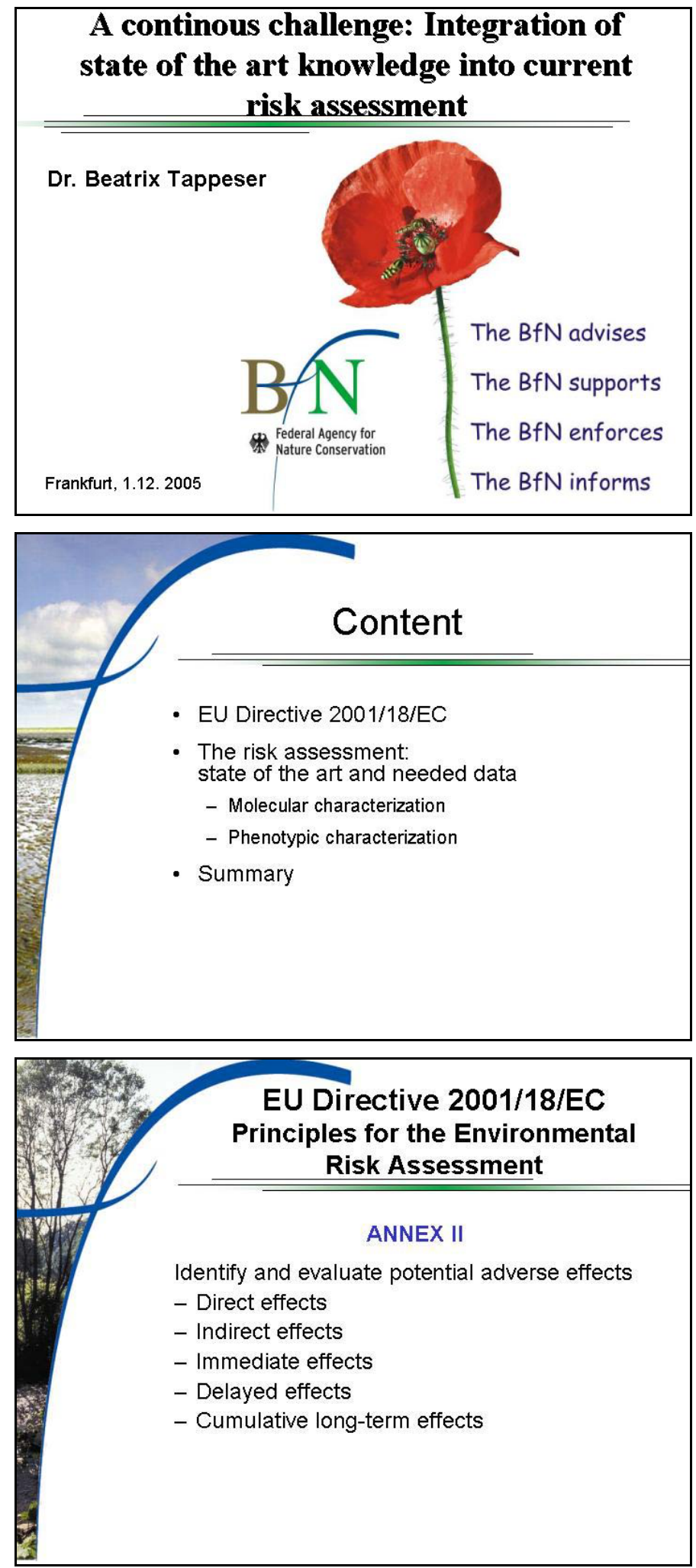

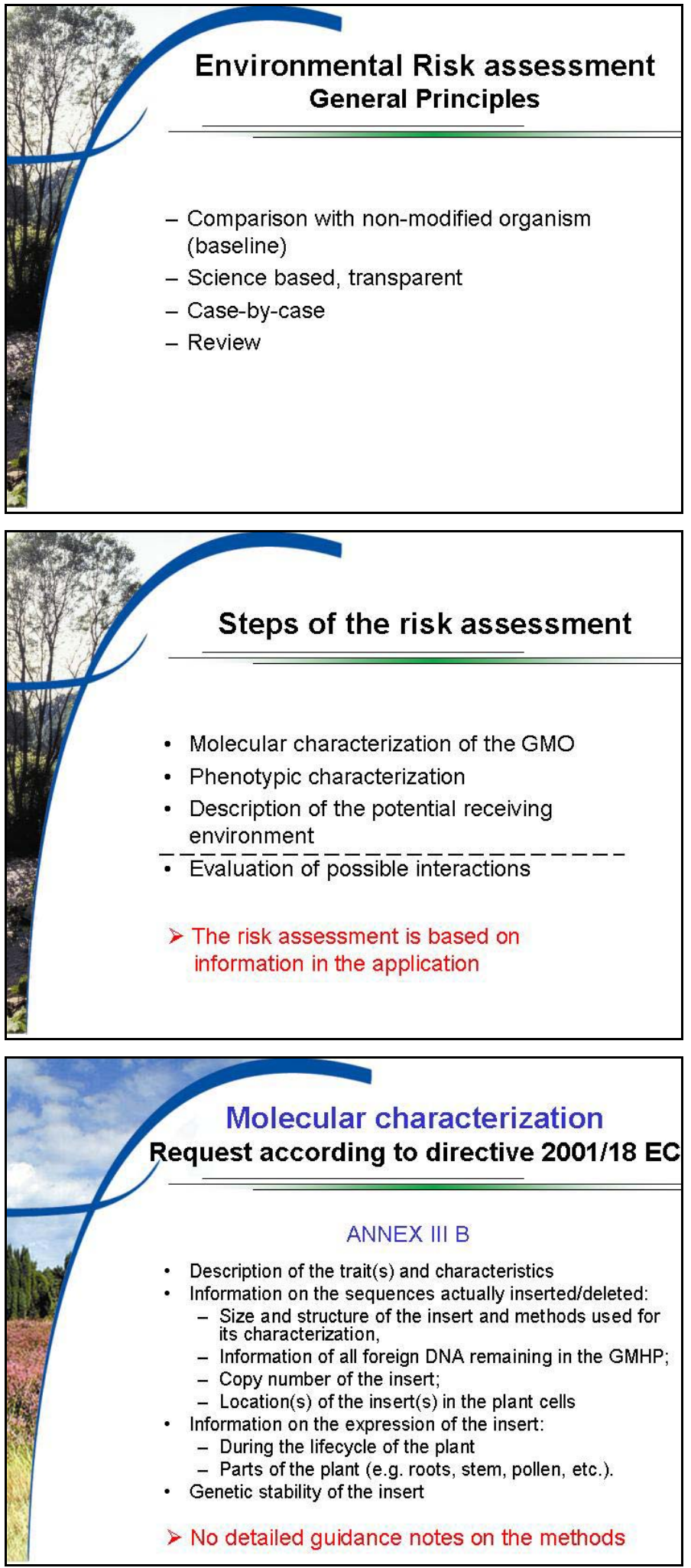

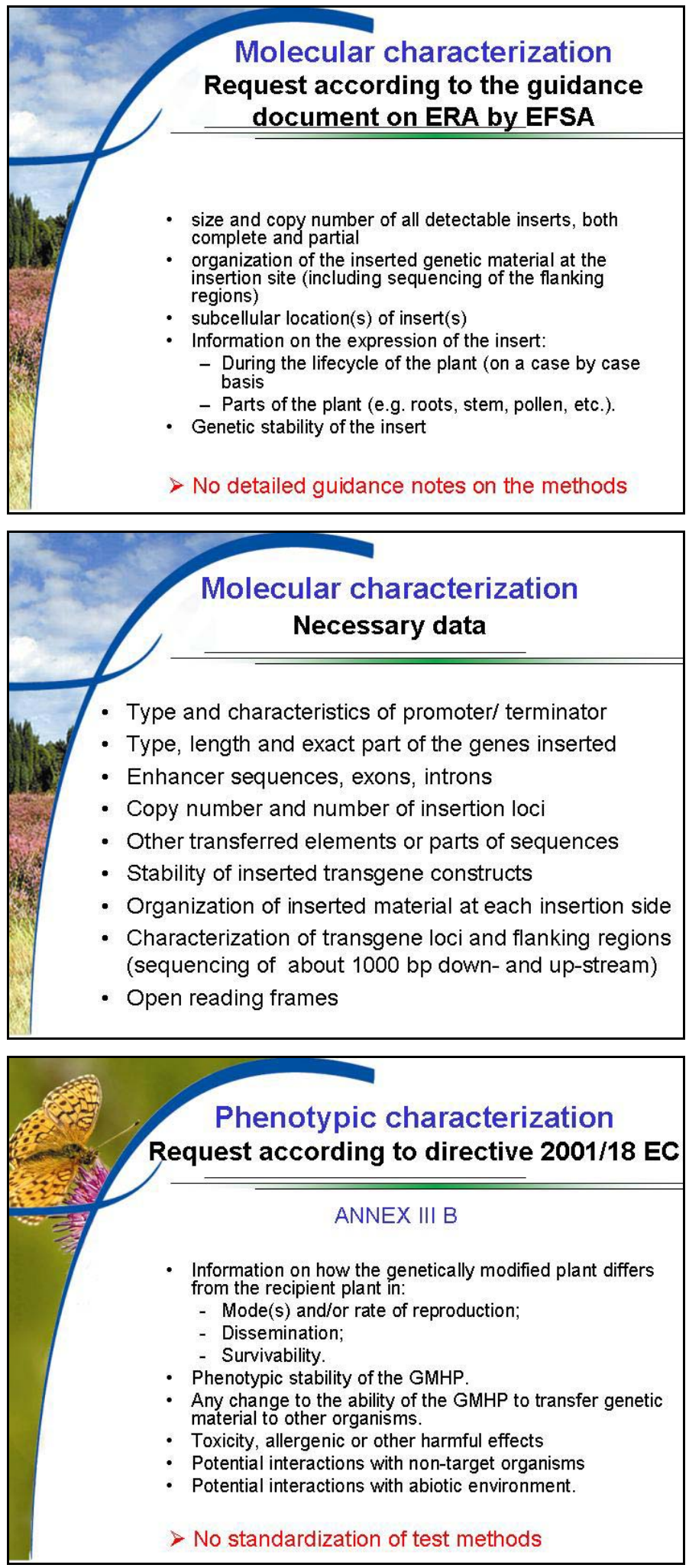

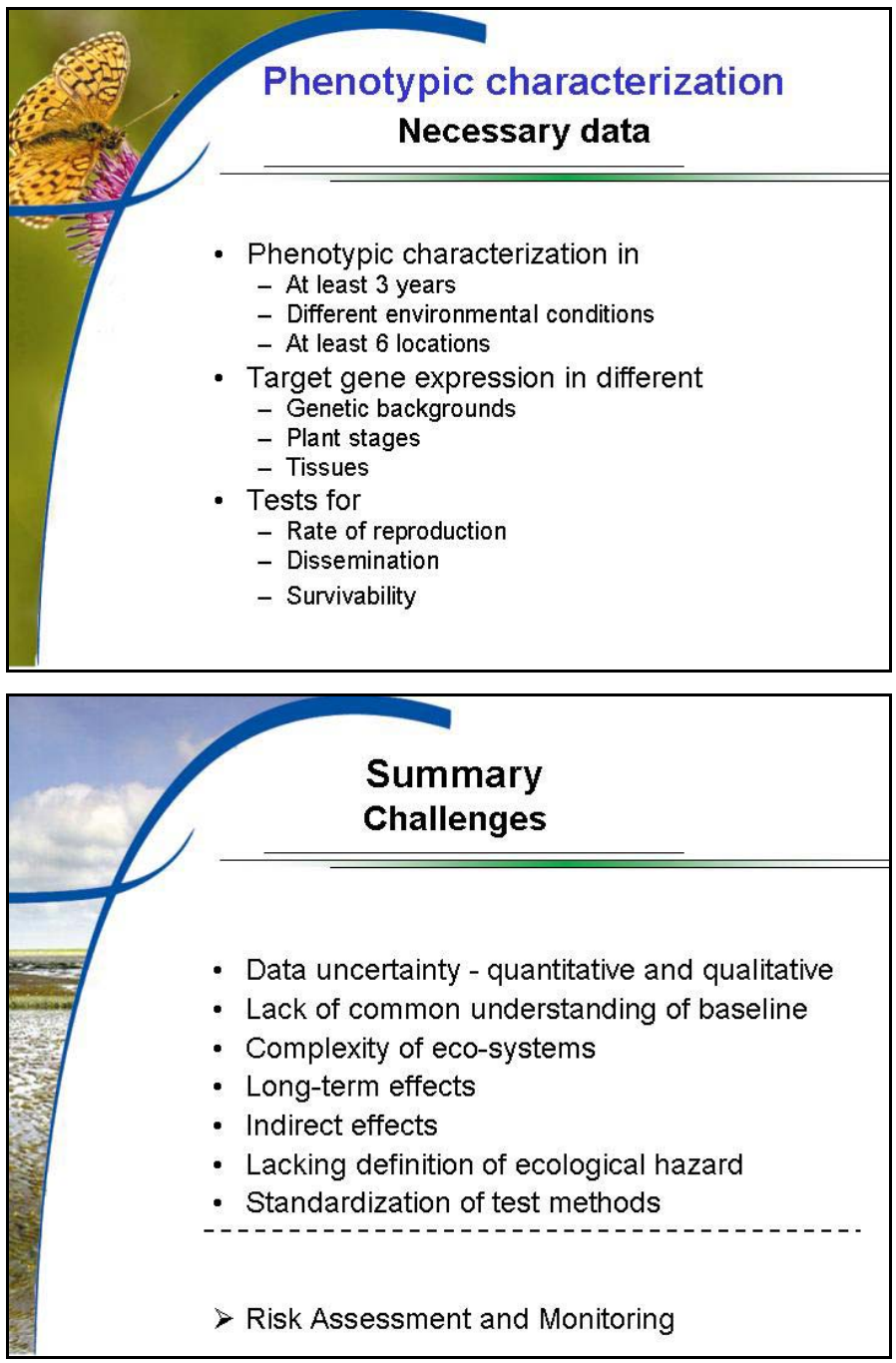

A continous challenge: Integration of state of the art knowledge into current risk assessment

Many thanks for your attention

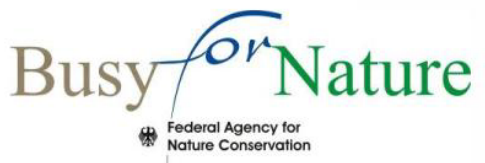

Dr. Beatrix Tappeser

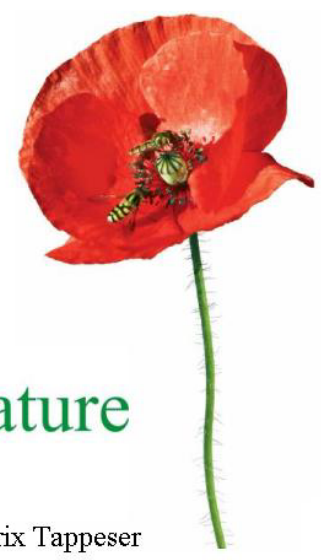




\section{Outlook}

Several uncertainties are inherent to the genetic engineering of plants. These new insights should be taken into account before releasing GMOs into the environment. It is however questionable whether GMOs should be tested in the open fields and commercially released into the environment at all.

Seen the continuous approvals that the European Commission is granting, several concrete demands arose from conference:

- The GMOs approved until now should undergo an in depth re-evaluation. Safety concerns not only apply for the genetically modified maize Bt 176, Bt11, T 25, GA 21 but also for the Roundup Ready resistant soybean.

- There is a need of a systematic research on unintended effects and on side effects inherent to genetic engineering. This should be in fact conducted by the companies. Research is needed on the impact of genetic engineering on the complex and dynamic genome organisation and should systematically survey not only genetic and epigenetic alterations but also alternative splicing and the metabolism as well as the related potential risks, e.g. by unintended functions of proteins leading into physiological and or morphological alterations of the transgenic plants.

- Risk assessment has to be continuously improved in order to take into account new results. The today's risk assessment still focuses on the effect of the inserted gene on the environment and human health. Some consideration of the speakers on how to improve the current risk assessment are summarised in the Annex.

We wish there were a continuous debate on a precautionary approach on the GMO policy. Modern technologies such as genetic engineering of plants need continuous debates to decide what kind of uncertainties is acceptable. 


\section{Annex: Suggestions for the Risk Assessment of Transgenic Plants}

How to handle uncertainty in relation to the effects of GMO production and the assessment of such effects was the main topic of the questions and statements during the discussions at the conference. A key theme of the statements was the demand that knowledge gaps and the limits to predicting and controlling characteristics and effects of GMOs be analysed thoroughly and stated clearly in order to improve current risk assessment guidelines and procedures as soon as possible.

The European Commission's guidance notes 2002/623/EC ${ }^{4}$ for the environmental risk assessment of GMOs contain a clause on uncertainty laying down that all the assumptions made in the risk assessment should be stated. However, in the application dossiers this requirement is normally not fulfilled.

The limits of the application of a certain potential product should be stated as well. This is particularly important in the case of products of genetic engineering for broad-scale markets, such as GM maize, in order to define the potential benefits and target groups of a product.

Speakers criticised the lack of transparency as a very important limitation in the risk assessment procedure. In some Member States of the EU, there seems to be limited access to the application dossiers even for people involved in the approval procedure. The application dossiers often cite reports that are not accessible. As a result, the methods cannot be judged. Another information gap is evident when only the conclusions and not the original data are shown. Patents seem to be less of an issue for the transparency of data. What is rather problematic is that in many cases companies claim confidentiality in fields where patent protection does not apply. For example, general confidentiality has been claimed for the design of animal testing protocols. Such a lack of information makes it impossible to repeat tests.

Moreover, the tests conducted for the risk assessment often are not state of the art. The molecular, physiological, metabolic and nutrition tests are regularly outmoded and the statistical methods used for significance analysis have a very low discrimination power (see the case of MON 863 nutrition experiments). This last fact means that differences may be declared statistically insignificant which would indeed be significant if analysed with different statistical programmes.

\footnotetext{
${ }^{4}$ 2002/623/EC Commission Decision of 24 July 2002 establishing guidance notes supplementing Annex II to Directive 2001/18/EC of the European Parliament and of the Council on the deliberate release into the environment of genetically modified organisms and repealing Council Directive 90/220/EEC:

"ERA has to take into account uncertainty at various levels. Scientific uncertainty results usually from five characteristics of the scientific method: the variable chosen, the measurements made, the samples taken, the models used and the causal relationships employed. Scientific uncertainty may also arise from a controversy on existing data or lack of some relevant data. Uncertainty may relate to qualitative or quantitative elements of the analysis. The level of knowledge or data for a baseline is reflected by the level of uncertainty, which has to be provided by the notifier (assessment of uncertainty, including lack of data, knowledge gaps, standard deviation, complexity, etc.) in comparison with the scientific uncertainties in current practice."
} 
A limitation in the risk assessment is that the baseline for comparison is not well defined. In particular, for genetic analysis the parental line should be the counterpart for comparison and almost never is. For instance Monsanto uses the term "equivalent" to the parental genotype and almost never compares the transgenic plant with isogenic non-transformed material - this should always be done due to possible different interactions of the transgene with different genetic host backgrounds.

As for compositional analysis, some interpretations claim that several conventional varieties form the baseline. But organically grown varieties are not included. Compositional analysis will certainly show a significant difference between organically and conventionally grow varieties. A general point is that compounds vary greatly depending on the variety but also on environmental conditions. Thus changes are very often interpreted as being the normal variation. Only beyond this variation will a difference be recognised as being significant and more detailed analysis be demanded. However, very often data are missing or reference data were generated with different methods that are less sensitive than methods available today. It may also be unclear which parts of the plants have been used to perform the compound analysis, e.g. whether parts of the seeds or the whole seeds or other tissue was chosen. As the plants may be grown under different conditions in terms of different local environments and year-on-year changes, experiments need to be organised in a way which allows analysis of the effects of these variables. We still do not know the possible interactions of different concentration levels of different compounds.

In addition to the question of how to evaluate those changes, differences in plant behaviour and possible risks will vary from transgene to transgene and from insertion to insertion as any insertion of a foreign gene can lead to changes in genome fluidity or epigenetic effects which do not occur with traditional breeding. However, so far data to compare GMOs and conventional varieties are lacking. Gilles-Eric Seralini once proposed comparing proteomics after natural breeding and after genetic engineering but this has not been done yet.

Last but not least, the evaluation performed in the risk assessment contains a normative aspect, from which different perspectives emerge. Here again, the underlying assumptions or hypotheses should be stated clearly but usually are not.

Some speakers are very concerned about the centralised procedure of GMO application according to Regulation $1829 / 2003^{5}$ that does not enforce transparency. The most relevant change from the earlier system is that in the decentralised procedure under Directive 2001/18/EC fifteen people per country reviewed the application dossiers whereas now, only fifteen people in total will have access to the whole document in time. In addition, the GMO panel of the EFSA does not necessarily have to justify its position if comments by Member States are not taken into account.

\footnotetext{
${ }^{5}$ Regulation (EC) No. 1829/2003 of the European Parliament and of the Council of 22 September 2003 on genetically modified food and feed
} 
Speakers outlined some proposals that should urgently become a minimum set of standards for the commercial application dossiers. However, the following proposals must be considered a preliminary shortlist of desirable improvements in the risk assessment. These proposals are not worked out in the form of technical protocols.

It is important to note that the following list is not exhaustive and needs completion! In particular, it does not discuss requirements for environmental risk assessment. Substantial improvements need to be made to assess the ecological impact of GMOs as well.

\section{Thorough molecular characterisation}

In the molecular characterisation of GM plants, the determination of copy numbers follows outmoded methods and sequences are seldom reported. According to the new knowledge gained recently on transgene stability and expression, the molecular characterisation should involve the following:

- Southern's blot analysis should be carried out using not only the whole construct but also parts of the construct in order to examine whether the sequence has been fragmented or not. Fragments should also be sequenced and assessed for unintended products of fragmentation.

- Flanking sequences should be obtained both for the whole insert and for possible fragments using adapted PCR methods. The number of copies of the whole sequence should be obtained with real time PCR both on the whole sequence and on fragments, thus showing whether fragments have been moving in the genome and might possibly replicate.

- Sequencing should be carried out on all the lines commercialised to find out whether major re-arrangement has been occurring during crosses leading to new transgenic lines, particularly in maize.

- $\quad$ Transcripts of the introduced sequence should be analysed, e.g. by RT-PCR. A special focus should be placed on aberrant RNAs. In case of unintended RNA, implications should be assessed carefully. This may be covered by a proteome analysis; such an analysis should be carried out as unwanted new proteins may be synthesised.

- Inter-individual variation particularly in unstable sequences such as that of CaMV should also be assessed. Their significance for gene expression should be evaluated.

\section{Detailed requirements for phentotypic characterisation}

For phenotypic characterisation, data from at least three years and at least six locations that represent different environmental conditions should be considered. 
The compositional analysis should be performed from plants grown under various conditions. For each testing setting the transgenic plant should be cultivated under conditions identical to those of the counterpart, the parental, completely isogenic nonGM line.

\section{Long-term animal testing ${ }^{6}$}

It was noted that a consortium of people should be established to define the adequate testing methods for animal tests. The process of developing recommendations for testing methods should be absolutely transparent. The minutes and protocols and the statistical procedures followed should be publicly accessible so that advantages, disadvantages or limitations as well as validity become apparent.

The diet should be carefully balanced so that the animals receive the same amount of an iso-proteinic and iso-energetic diet containing all the appropriate compartments by pair-feeding. Care must be taken to avoid nutritional imbalance.

In the comparisons, it is essential to have more appropriate control groups in addition to the parental control. There should be a control group fed on a diet containing a transgenic crop transformed with a transgene-free construct vector in which it is made certain that this has been inserted in the same place as in the transgenic line investigated. Another control is recommended in which the parental line diet is supplemented with the transgene product isolated from the transgenic crop.

In animal testing, a first step should be a short preliminary study and then a long-term, eventually a life-long study. It would be good to start with young, rapidly growing animals. They have to eat and have to make a normal development. Life-time studies should take samples at six months, a year, 18 months and two years. Long-term animal testing should include the investigation of several offspring of animals.

The observations of the animals should conform to the OECD guidelines for test No. 408. They need to involve multidisciplinary studies combining biochemistry, light microscopy histology, electron microscopy histology and also microbiology because of the intestinal bacteria. In addition to the OECD guidelines, animals should be weighed daily, urine and faecal samples should be assessed for net protein utilisation and feed ratio utilisation, blood samples should be taken and hormone studies should be undertaken (see also Pusztai 2002).

\footnotetext{
${ }^{6}$ Editor's note: Though this was not mentioned at the conference, the demand for long-term animal testing causes a dilemma from an ethical point of view. However, so far, there are no alternative methods that could replace the long-lasting tests in animals in order to examine unintended effects that might have chronic sublethal effects. For reasons of animal welfare, the development of reliable alternative methods should have high priority.

Alternative methods such as tests in cell cultures are restricted to single compounds that can be applied in defined concentrations. Those tests could however replace the 28-day feeding trials on rodents that are to be performed according to the EFSA Guidance Document to check the toxicology of the transgenic protein itself. Alternative test methods use cultured human liver and neuronal cells and expose them to single substances at different concentrations and for different exposure times. Then, DNA arrays are used to monitor the expression of genes in the cells that are markers of a particular pathological pathway, e.g. cell stress markers, DNA damage markers, cell cycle control markers etc.
} 
Differences should be checked as to whether they are transient or irreversible.

For transgenic plants designed to contain pesticides that they absorb and/or produce, toxicity tests according to 91/414/EEC, tests on mammals, during three months on three species, one year on one species and two years on another one (generally rat) should be performed. The testing should be performed with the herbicide tolerant plant that was grown with the herbicide treatment. This is because Glyphosate alone is not toxic, but together with the adjuvants mediates for new and toxic properties e.g. for placental cells.

\section{Minimum standard for genetic engineering?}

Another interesting approach was set out by Cesare Gessler for concrete minimum requirements at the genetic level. According to him, genes foreign to the species should not be used but only species' own DNA. In addition, researchers need to be able to define exactly at which site in the genome the gene construct will be inserted, which should ideally replace a certain gene segment with the new gene construct. This corresponds with other demands for novel and more refined methods that should replace the present crude methods of genetic engineering. However, the use of species' own DNA will not prevent insertional disturbances in the genome. Hence, any new testing procedure must take into account the real possibility of insertional mutagenesis under any conditions. Modern techniques such as proteomics and metabolomics should be further developed.

OECD (1998): Test No. 408: Repeated Dose 90-Day Oral Toxicity Study in Rodents. OECD Guidelines for Testing of Chemicals / Section 4: Health Effects: 1-10.

Pusztai A (2002): Can science give us the tools for recognizing possible health risks of GM food? Nutrition and Health 16: 73-84. 